\title{
Accounting for traffic speed dynamics when calculating COPERT and PHEM pollutant emissions at the urban scale
}

\author{
Delphine Lejri ${ }^{1}$, Arnaud Can ${ }^{2}$, Nicole Schiper ${ }^{1}$, Ludovic Leclercq ${ }^{1}$ \\ ${ }^{1}$ Univ. Lyon, ENTPE, IFSTTAR, LICIT, F-69518 Vaulx-En-Velin, France \\ ${ }^{2}$ IFSTTAR, AME, LAE, F-44344 Bouguenais, France
}

\begin{abstract}
Coupling a traffic microsimulation with an emission model is a means of assessing fuel consumptions and pollutant emissions at the urban scale. Dealing with congested states requires the efficient capture of traffic dynamics and their conditioning for the emission model. Two emission models are investigated here: COPERT IV and PHEM v11. Emission calculations were performed at road segments over 6 min periods for an area of Paris covering $3 \mathrm{~km}^{2}$. The resulting network fuel consumption (FC) and nitrogen oxide (NOx) emissions are then compared. This article investigates: (i) the sensitivity of COPERT to the mean speed definition, and (ii) how COPERT emission functions can be adapted to cope with vehicle dynamics related to congestion. In addition, emissions are evaluated using detailed traffic output (vehicle trajectories) paired with the instantaneous emission model, PHEM.

COPERT emissions are very sensitive to mean speed definition. Using a degraded speed definition leads to an underestimation ranging from $-13 \%$ to $-25 \%$ for fuel consumption during congested periods (from $-17 \%$ to $-36 \%$ respectively for NOx emissions). Including speed distribution with COPERT leads to higher emissions, especially under congested conditions $(+13 \%$ for FC and $+16 \%$ for NOx). Finally, both these implementations are compared to the instantaneous modeling chain results. Performance indicators are introduced to quantify the sensitivity of the coupling to traffic dynamics. Using speed distributions, performance indicators are more or less doubled compared to traditional implementation, but remain lower than when relying on trajectories paired with the PHEM emission model.
\end{abstract}

\section{Highlights}

- The mean speed definition has a considerable impact on COPERT FC and NOx emissions, even at the network scale.

- COPERT functions are adapted to richer traffic information (speed distribution).

- Modeling chain comparison: traffic microsimulation is paired with PHEM and COPERT.

\section{Keywords}

Traffic microsimulation, network emission modeling, mean speed definition, vehicle kinematics representation, comparison of COPERT and PHEM 


\section{Introduction}

Road traffic emissions have dramatic local and global effects. Pollutants such as Nitrogen Oxides $\left(\mathrm{NO}_{\mathrm{x}}\right)$ and Particulate Matter (PM) have known detrimental impacts on human health, including respiratory and cardiovascular diseases (Shaughnessy et al., 2015), while Carbon Dioxide $\left(\mathrm{CO}_{2}\right)$ emissions greatly contribute to global warming. Accurate trafficrelated emission estimations are thus crucial to assess their evolutions over several years, and to quantify the environmental impact of sustainable transportation policies such as lowemission zones and traffic regulation strategies. Emission estimations should be based on models developed for the given scale of interest, which can range from very local (e.g., for the assessment of certain road traffic facilities) to global investigations (e.g., for compiling inventories), and therefore rely on both relevant representations of road traffic and vehicle emissions. A detailed review of vehicle emission models can be found in (Smit et al., 2010), while (Fallah Shorshani et al., 2015) provide a review of the complete modeling chain (traffic, emission, dispersion and storm water).

The main current research efforts focus on the urban scale, because urban road traffic causes the vehicle kinematics that generate the highest emissions, namely rapid speed variations and congestions, and they are the most difficult to take into account (Ma et al., 2015)(Ahn and Rakha, 2009), (De Vlieger et al., 2000) (Zhang et al., 2011) (Qu et al., 2015). Models based on vehicle representations have been developed to overcome these problems. Microscopic traffic simulation provides detailed vehicular kinematics, namely an estimate of the $1 \mathrm{~s}$-evolution of speed and acceleration for each vehicle on the network. Thus it can capture congestion effects at the finest spatial and temporal resolution. The estimated traffic data are provided for an instantaneous emission model which uses speed profiles (Chen and Yu, 2007) or derived indicators to estimate emissions (Frey et al., 2010; Jiménezpalacios, 1999). Such modeling has been advantageously used for assessing traffic regulation strategies such as traffic signal synchronization and speed reduction (Madireddy et al., 2011).

However, biases introduced by this coupling have been highlighted, especially concerning simplified vehicle trajectories (Vieira da Rocha et al., 2013) and calibration processes (Jie et al., 2013) (Xu et al., 2016) (Lu, 2016). Integrating emissions in the optimization function can help to reduce these biases (Vieira da Rocha et al., 2015).

Microscopic emission models entail long computation times, which confine them to local investigations. Aggregated models have been developed for broader scale assessments. These models rely on simplified kinematics variables, such as vehicle mean speed (Samaras and Geivanidis, 2005), which is the traffic parameter that most influences emissions (Hansen et al., 1995) (Ericsson, 2001) (Joumard et al., 2000) (André and Hammarström, 2000) (André and Rapone, 2009).

Models based on mean driving speeds are less successful with congested situations (R. Smit, Brown, \& Chan, 2008). Indeed, these models implicitly take varying levels of congestion into account, depending on the average speed and the road type chosen (and the driving cycle associated). But they have not been developed to produce accurate local emission predictions. Several alternatives have been proposed to overcome this drawback. (Robin Smit et al., 2008) reconstructed a speed distribution from the available mean speed on road 
sections. (Pitsiava-Latinopoulou et al., 2014; Samaras et al., 2014) proposed using aggregated models at spatial scales smaller than the scale to which they were initially dedicated, up to the road segment scale. However, this calls into question the temporal and spatial scales at which the modeling choices made remain relevant.

(Samaras et al., 2017) proposed an evaluation for a $1.6 \mathrm{~km}$ long urban corridor based on micro-scale data (models and measurements). The authors showed that average speed is strongly correlated with congestion. Therefore, the aggregate emissions model (COPERT 5) is congestion sensitive and more relevant for depicting loaded rather than fluid situations and their effects on EURO 5 diesel vehicle fuel consumption.

In essence, road sections and short time scales (traditionally 6 min periods, with electromagnetic loop measurements) are relevant for observing traffic on an urban network. This scale provides information on vehicle dynamics that characterize congestion through aggregate traffic variables and raises questions regarding the emission model that should be interfaced with these traffic data at this scale of interest. Therefore, it seems crucial to highlight emission-modeling representations that are compatible with the outputs of the traffic microsimulation.

The key objectives of this article are: (i) to evaluate the impact of traffic information processing on the emissions obtained with an aggregated model, and (ii) to compare the emissions over the network obtained with an aggregated emission model and an instantaneous one. Section 2 presents the simulation framework and the models tested. Section 3 presents alternatives to usual aggregated models. Sections 4 and 5 compare the emission estimations for a case study. Finally, section 6 concludes on modeling choices for urban emission assessment.

\section{Material}

Coupling traffic variable definitions with emission models is tested by comparing estimated fuel consumptions and NOx emissions over a simulation network. The tested emission models are COPERT and PHEM, which rely on average travel speeds and instantaneous individual speeds, respectively. The versions of COPERT and PHEM used are COPERT IV and PHEM v11, respectively (see section 2.2). The traffic data required are provided by the dynamic traffic platform Symuvia, which can supply input data from individual vehicle trajectories to aggregated speeds for each vehicle category at given locations on the network and at any temporal resolution.

\subsection{Traffic simulation}

\subsubsection{Traffic model and simulation}

The network studied is a $3 \mathrm{~km}^{2}$ zone covering part of the municipalities of Le Perreux-surMarne and Neuilly-Plaisance in the Paris region. The traffic network, displayed in Figure 1, was selected for its wide range of traffic conditions. Two structural arterials, "Boulevard d'Alsace-Lorraine" and "rue Pasteur", both oriented in the east-west direction, cross the site and feed it with dense traffic. The rest of the site is composed of a few main corridors 
(shown in blue in Figure 1), and a large number of residential streets crossed by light volumes of traffic limited in speed to $30 \mathrm{~km} / \mathrm{h}$.

The traffic microsimulation was implemented in the Symuvia platform ${ }^{1}$, which gives access to the position, speed and acceleration of each vehicle on the network with a 1s-resolution. Vehicle routing choices are governed by a dynamic traffic assignment model, which guides each vehicle in the network on the route that minimizes its travel time to its initially assigned destination. Vehicle movements at the microscopic scale are governed by a set of rules, including car-following modeling (Leclercq, 2007a, 2007b), lane-changes (Laval and Leclercq, 2008) and specific movements at intersections (Chevallier and Leclercq, 2007). The platform also copes with the cohabitation on the network of vehicles with different kinematics, including passenger cars, buses and heavy-duty vehicles. The question of using the platform outputs for pollutant emission estimations was addressed in (Vieira da Rocha et al., 2013).
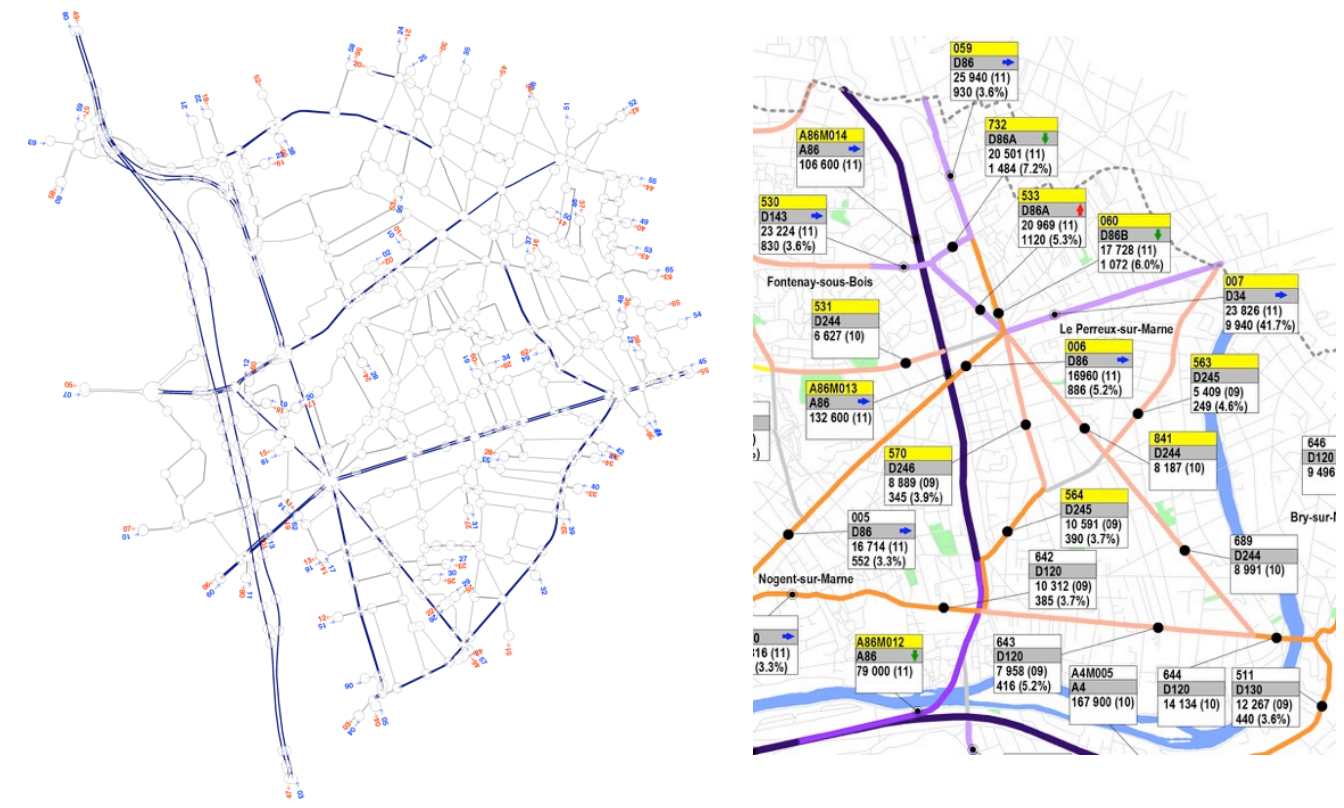

Figure 1. Simulation network implemented in Symuvia. Left: road network and Origin/Destination traffic demands. Right: Mean weekday traffic counts for passenger cars and heavy duty vehicles

The simulation consists of 2.5 hours representing the morning rush hour. The OriginDestination matrix was calibrated with hourly traffic flow rates measured on typical weekdays at 24 locations of the network (see Figure 1). The calibration results are depicted in Figure 2.

\footnotetext{
${ }^{1}$ http://www.licit-lyon.eu/themes/realisations/plateformes/symuvia/
} 

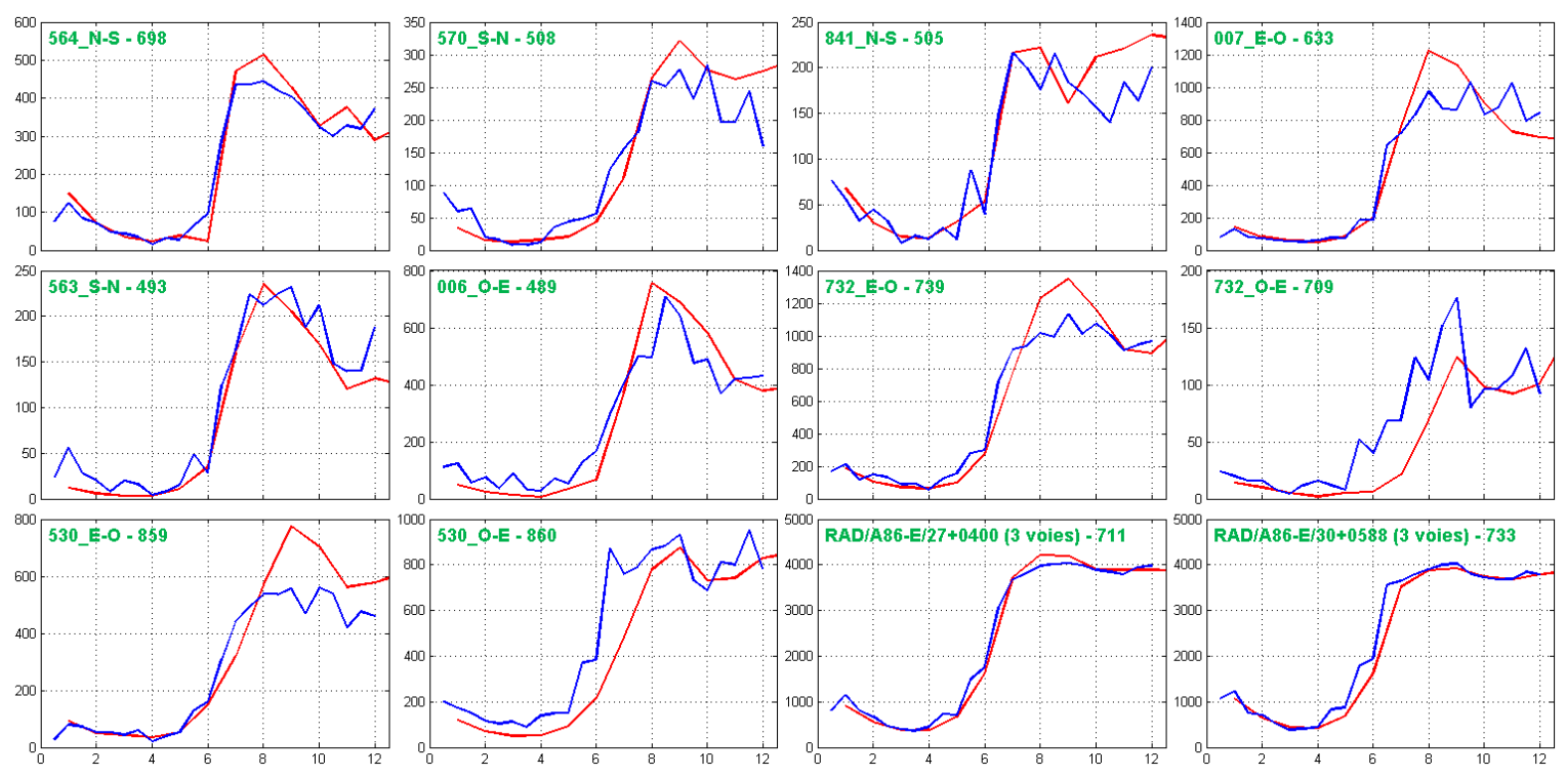

Figure 2 : measured (red) and estimated (blue) traffic flow rates (veh/h) over time (hours) at 12 locations.

\subsubsection{Traffic outputs}

The most refined available traffic outputs provided by Symuvia are the vehicle speeds and accelerations at each time-step ( $1 \mathrm{~s})$, for all the vehicles on the network. This traffic model has the particular advantage of avoiding the unrealistic accelerations that can be found in traffic microsimulation (Leclercq, 2007b). Indeed, the traffic simulator used - Symuvia produces simplified vehicle trajectories. However, it allows conforming to realistic speed and acceleration values, depending on the type of vehicle. Thus, each vehicle type is associated with a maximum acceleration per speed range. For example, between 20 and $30 \mathrm{~km} / \mathrm{h}$, light vehicles can accelerate by a maximum of $1 \mathrm{~m} / \mathrm{s}^{2}$, while heavy vehicles cannot accelerate by more than $0.6 \mathrm{~m} / \mathrm{s}^{2}$. Above $30 \mathrm{~km} / \mathrm{h}$, these limits decrease by $0.5 \mathrm{~m} / \mathrm{s}^{2}, 0.3 \mathrm{~m} / \mathrm{s}^{2}$ respectively. Figure 3 shows the speed-acceleration pairs experimented during the simulation under congested conditions for light and heavy vehicles.

These vehicle trajectories can be used directly to calculate emissions with PHEM (including a default gearshift model), or aggregated into traffic variables in order to correspond to the required COPERT inputs (see section 2.2). In both cases, the traffic outputs will be provided for each road segment with a 6 min-resolution, and will be interfaced at that scale with emission models. 

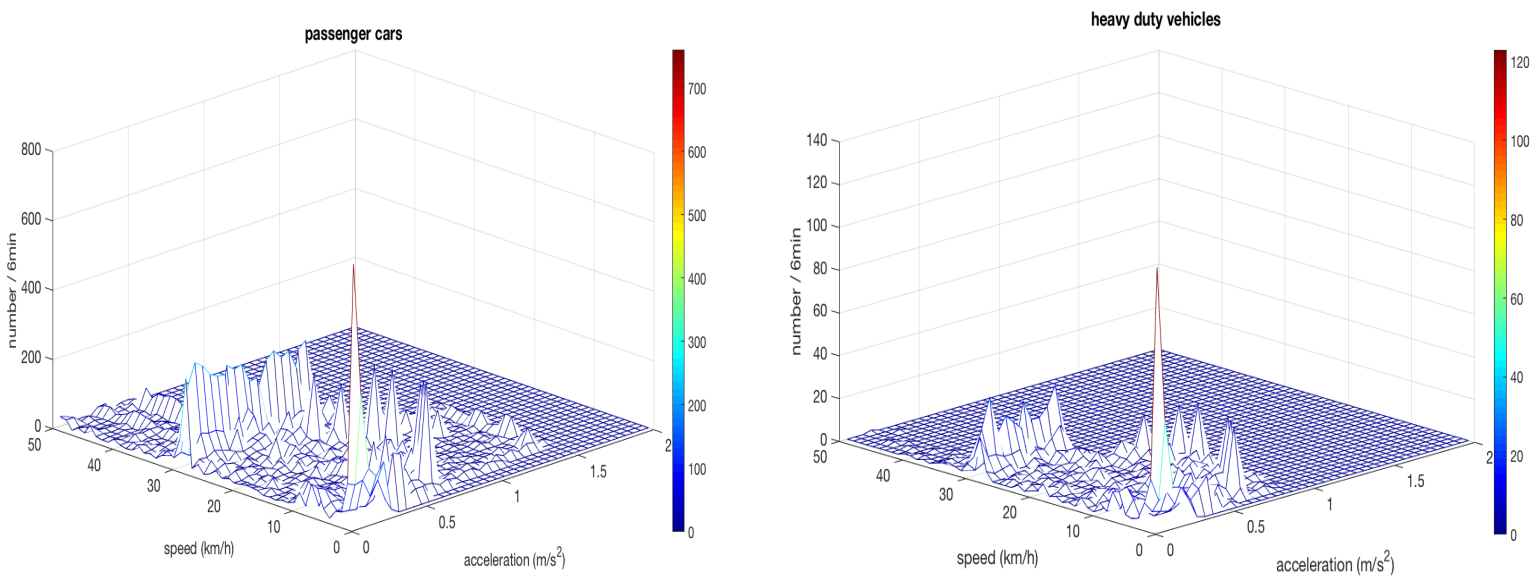

Figure 3 Speed acceleration distributed under congested conditions for light (left) and heavy (right) vehicles

When a traffic microsimulation is available, we can characterize the spatial mean speeds most relevant for evaluating pollutant emissions. However, it is also possible to reproduce the case where the level of traffic information is less accurate and where the average speeds are characterized by electromagnetic loops. In this case, based on punctual mean speeds, emissions can be assessed as can the deviations from a more comprehensive traffic description observed in the same conditions.

In this paper, various speed definitions are compared for qualifying vehicle kinematics on each road segment, thus leading to an increasing level of detail:

1. The operational (or default) definition assumes that the average speed is the speed limit $\mathbf{V}_{\text {limit, }}$ which is the first operational information available.

2. The speed experimented at one specific location on the road segment $\mathbf{V}_{\text {punctual }}$ corresponds to the local measure performed for instance by electromagnetic loops. Three virtual positions are tested, corresponding to the following locations: $25 \%, 50 \%$ and $75 \%$ of each segment length, from the beginning of the road segment. Associating the speed on a road segment to $\mathbf{V}_{\text {punctual }}$ amounts to assuming that vehicle speeds are homogeneous along the segment.

3. The speed characterizing the vehicle kinematics on the whole road segment $\mathbf{V}_{\text {spatial }}$ can be determined using Edie's definition (Edie, 1965), in which the spatial speed is the ratio between the total travel distance and the total spent time. This speed definition is the most accurate and compatible with the emission estimations, but unfortunately it relies on data not available on a real network.

These three speed definitions can differ significantly, in particular under congestion, as shown in Figure 4. As expected, the speed limit $V_{\text {limit }}$ overestimates the actual speeds. The wider the vehicle mean speed distribution on the road segment, the larger the errors. Punctual loops also result in speed overestimations, a long acknowledged bias determined by the location of the loop. Indeed, at the urban scale, loops close to signals are subject to much more congestion. The impact of these different speed definitions on the resulting emission errors is investigated in section 4. 

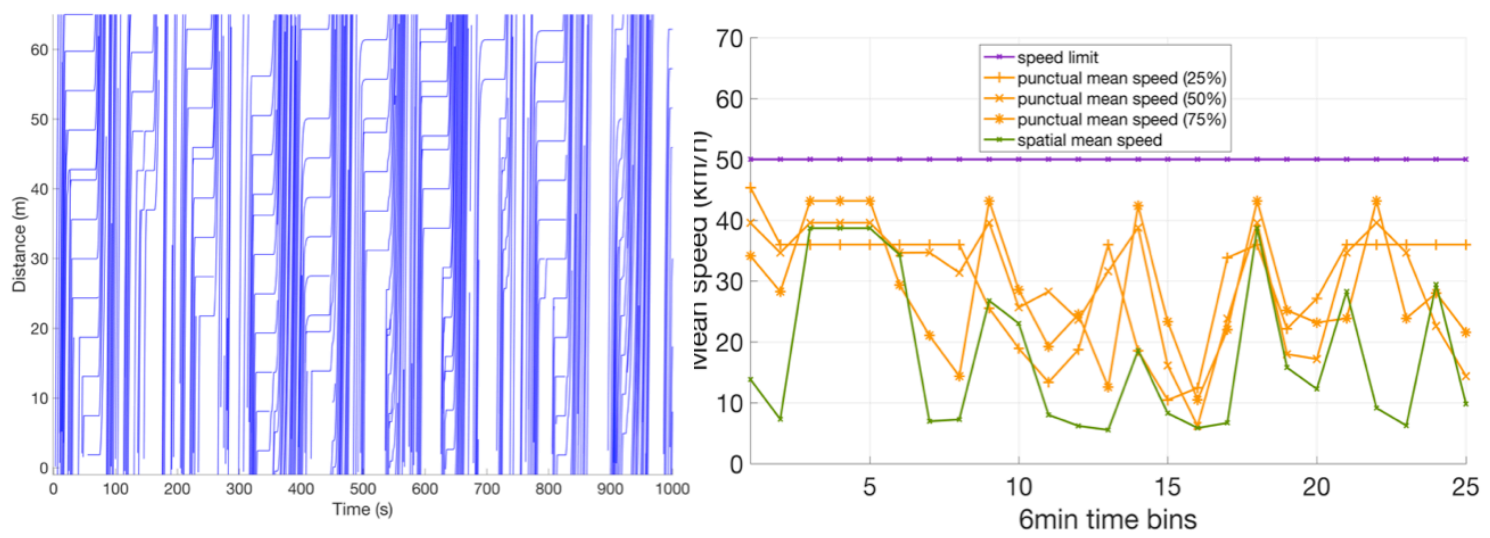

Figure 4 : Left: extract of the vehicle trajectories provided by Symuvia. Right: Mean speed evolution according to its definition on the arterial "Boulevard d'Alsace-Lorraine".

\subsection{Emission models}

These traffic variables are used by the emission models to estimate fuel consumptions (FC) and NOx emissions in the network. The two types of emission model investigated are the modal model PHEMv11 and the aggregated model COPERT IV. Only hot exhaust emissions are considered. Indeed, although cold-start and evaporative emissions can amount to a nonnegligible proportion of total emissions, it can be assumed that both the potentially initiated traffic strategies and the vehicle kinematics reproduced affect them in the same way as they affect hot exhaust emissions.

Vehicle emissions strongly depend on the vehicle's characteristics, namely the vehicle category (passenger cars, buses, etc.) and, within each category, fuel type, age, technology, and emission standard (Euro 4, Euro 5, etc.) of the vehicle. The vehicle fleet is one of the parameters set throughout the study. This fleet is the French urban fleet for the year 2015 obtained from the IFSTTAR fleet updated in 2013. This passenger car fleet is composed of 30\% EURO 5 diesel vehicles and 24\% EURO 4 diesel vehicles, whereas the light commercial vehicle fleet is composed of $45 \%$ EURO 5 diesel vehicles and 30\% EURO 4 diesel vehicles. The vehicle classes are divided as follows to fit the traffic microsimulation: $82 \%$ passenger cars, $14 \%$ light commercial vehicles, $3 \%$ heavy duty vehicles and $1 \%$ urban buses. The interpretation of this car fleet by both modeling approaches differs, which can be a source of discrepancies between the emissions estimated.

\subsubsection{COPERT IV}

COPERT IV has been widely used in most European Countries for compiling national emission inventories (Ntziachristos et al., 2009), but it is also increasingly used for emission modeling at the street level (Borge et al., 2012). Concretely, this requires relying on the average speeds and travel distances provided by a traffic model or measurements at each period, for each road segment and vehicle category, and then applying the COPERT speed continuous functions over each of these road segments. However, this use at spatial scales lower than 
the driving cycles is subject to question. Indeed, the actual road segment speed distributions might differ from those of the driving cycles, and lose representativeness for very small samples or specific traffic conditions (e.g. in the vicinity of intersections), yielding inaccurate emission estimates.

COPERT relies on mean driving speed and travel distance (total distance in $\mathrm{km}$ travelled per vehicle for a given period) to predict the related exhaust emissions. The total emissions are calculated as the product of the travel distance and the unitary emission factors, according to formula (1). Unitary emission factors consist of speed continuous functions that have been constructed over driving cycles of about $6 \mathrm{mn}$-length, which are representative of the traffic conditions encountered (André and Rapone, 2009). These unitary emission functions are defined for each pollutant $k$ and each vehicle class $c$ (e.g. passenger cars, light duty vehicles, buses and heavy duty vehicles). The unitary emission function of a specific class is obtained by using a weighted average of the vehicle technologies that compose the class. Consequently, the emissions $\mathrm{E}^{\mathrm{k}, \mathrm{c}}(\mathrm{g})$ are calculated as:

$$
\mathrm{E}^{\mathrm{k}, \mathrm{c}}=\mathrm{D}^{\mathrm{c}} \cdot \mathrm{F}^{\mathrm{k}, \mathrm{c}}\left(\mathrm{V}^{\mathrm{c}}\right)
$$

with $\boldsymbol{F}^{k, c}$ being the unitary emission factor $(\mathrm{g} / \mathrm{km})$ of pollutant $k$ and vehicle class $\mathrm{c}$, $D^{c}$ the total travel distance $(\mathrm{km})$ and $V^{c}$ the mean speed for vehicle class $\mathrm{c}$.

Thus, within a vehicle class, the model considers the same mean vehicle (obtained for a fixed car fleet) whatever the period and the road segment size. The model then omits the dispersion in emissions due to the variability in the actual car fleet observed for small periods and road segments, i.e. when the number of observed vehicles is small.

\subsubsection{PHEM v11}

PHEM (Passenger Car and Heavy Duty Emission Model) calculates the fuel consumption and emissions of vehicles with a 1s-time resolution, based on their longitudinal dynamics and on engine emission maps (Hausberger, 2003; Hausberger et al., 2003). The model first provides an estimate of the 1s-engine power of a vehicle, on the basis of its speed time-series and the road gradient. The engine speed is estimated using transmission ratios and a gear shift model. Engine emission maps then allow estimating the time evolution of fuel consumptions and airborne pollutant and particulate matter emissions. The model also includes transient correction functions, and a cold start tool. Cold start emissions will however be disregarded to enable comparison with COPERT.

PHEM is thus appropriate for coupling with dynamic traffic platforms intended to provide vehicle trajectories. Such coupling has been performed on several occasions to test the impact on emissions of road traffic strategies that modify vehicle kinematics behavior (Zallinger, 2009). However, the inadequacy between the high traffic data resolution required and the available dynamic traffic model outputs, which are much less refined or subject to inaccuracies, can lead to significant discrepancies (Vieira da Rocha et al., 2015).

In PHEM, each individual vehicle of the simulation is associated with one specific vehicle that composes the car fleet, with its own vehicle technology. Thus, in theory the model copes with the small-scale variations of the actual car fleets observed; consequently, periods with similar vehicle kinematics conditions can result in different emissions. The fit between the actual and the modeled emission variability is, however, a key factor. 


\section{Applying COPERT at the road segment scale}

COPERT emission factors are continuous and non-linear functions of vehicle average speeds. Therefore, their application at the road segment scale and with small periods first requires evaluating the sensitivity of the model to mean speed variations. Second, it requires adaptations to handle the mean speeds below $10 \mathrm{~km} / \mathrm{h}$ that are frequent at small time and space scales, and cope with the vehicle trajectories provided by the dynamic traffic simulation. Adaptations to COPERT emission functions are proposed in this section to overcome these issues where appropriate.

\subsection{Sensitivity of COPERT to mean speed}

This section quantifies the impact of variations in the estimated mean speeds on the emission factors estimated within COPERT, thanks to formula (1). Mean speeds are relatively low under urban driving conditions, and emission factors are highly variable within this speed range (Ntziachristos et al., 2009). If we hypothesize that the travel distance is associated with small variations whose effects can be neglected, then the relative errors on emissions are only due to the bias on mean speed and can be expressed as:

$$
\frac{|\Delta \mathrm{E}|}{\mathrm{E}}=\left|\frac{\partial \mathrm{E}}{\partial \mathrm{v}}\right| \frac{\mathrm{V}}{\mathrm{E}} \frac{|\Delta \mathrm{V}|}{\mathrm{V}}
$$

These relative emission errors in terms of speed errors are depicted for FC and NOx emissions in Figure 5. The figure highlights the low accuracy of speed estimates needed for actual speeds around $70 \mathrm{~km} / \mathrm{h}$, which can be explained by the known low variability of emissions in this speed range. Conversely, the need for accurate speed estimates increases at low speeds.
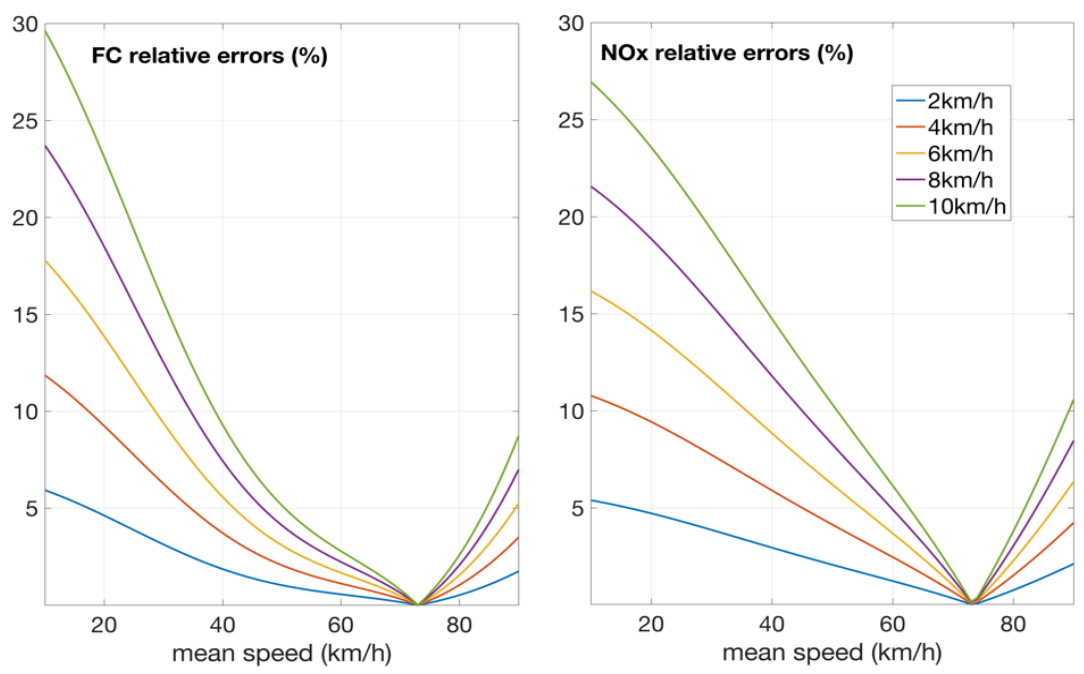

Figure 5 Relative errors on fuel consumption and NOx emissions related to mean speed variations from 2 to $10 \mathrm{~km} / \mathrm{h}$

For example, at $30 \mathrm{~km} / \mathrm{h}$, a $2 \mathrm{~km} / \mathrm{h}$ error on the mean speed estimates will lead to a $3.1 \%$ error on the FC estimate and a 3.9\% error on the NOx emission estimate. At the same time, a $10 \mathrm{~km} / \mathrm{h}$ error will lead to a $15.7 \%$ error on the FC estimate and a $19.3 \%$ error on NOx emissions. These percentages correspond to errors on the mean speed values commonly 
reached through both modeling and in situ measurements. Thus, at the urban scale, such levels of bias are normally expected, especially at small time and spatial scales.

\subsection{Adapting the COPERT model}

\subsubsection{Coping with low mean driving speed within COPERT}

In Figure 6, the FC and NOx emission factors $\mathbf{F}^{k}$ (in $\mathrm{g} / \mathrm{km}$ ) are drawn in terms of the mean speed. The COPERT model handles only mean speeds higher than $10 \mathrm{~km} / \mathrm{h}$, although mean speeds below $10 \mathrm{~km} / \mathrm{h}$ can be encountered at the road segment scale for some of the $6 \mathrm{~min}$ periods. As emissions are definitely not insignificant at that speed range, the COPERT emission curves are extended by either maintaining the EF value at $10 \mathrm{~km} / \mathrm{h}$ (straight extension), or drawing out the EF curve fitted with a $4^{\text {th }}$ degree polynomial (polynomial extension). The consequences of these choices are discussed in section 4.
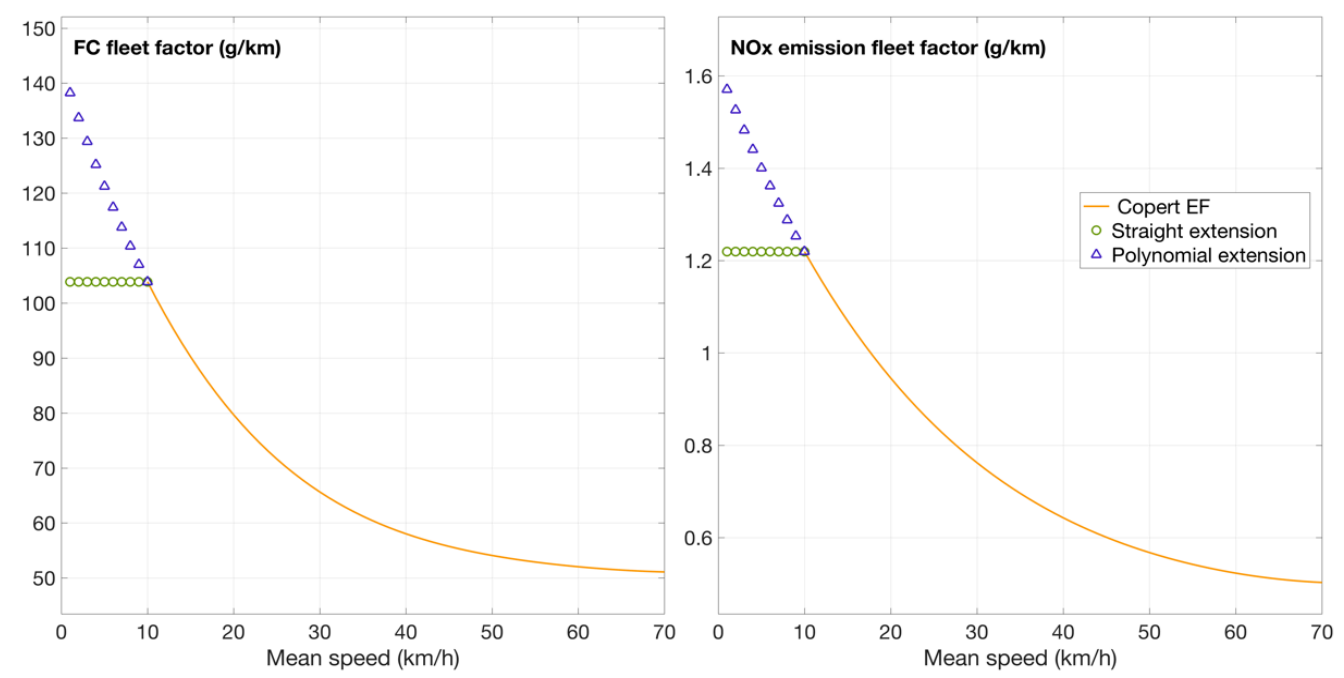

Figure 6 Extended emission functions for low mean speed (left: FC function; right: NOx function)

\subsubsection{Instantaneous mean driving speed}

The dynamic traffic simulation makes it possible to describe the vehicle kinematics associated with a road segment and a period in a more detailed way than a mean driving speed. The distribution of time spent and the distribution of the travel distances per speed class are, for instance, available, possibly refining the emissions calculated with COPERT. However, the COPERT emission curves are not designed to accept such fine input data. The COPERT model is adapted in this section to make it compatible with high-frequency traffic data inputs. These adaptations consist in: (i) treating idling time separately, as it is a specific part of the speed class distribution, and (ii) rewriting the emission factor functions to reveal the dependency on instantaneous speeds rather than on spatial mean speeds. 

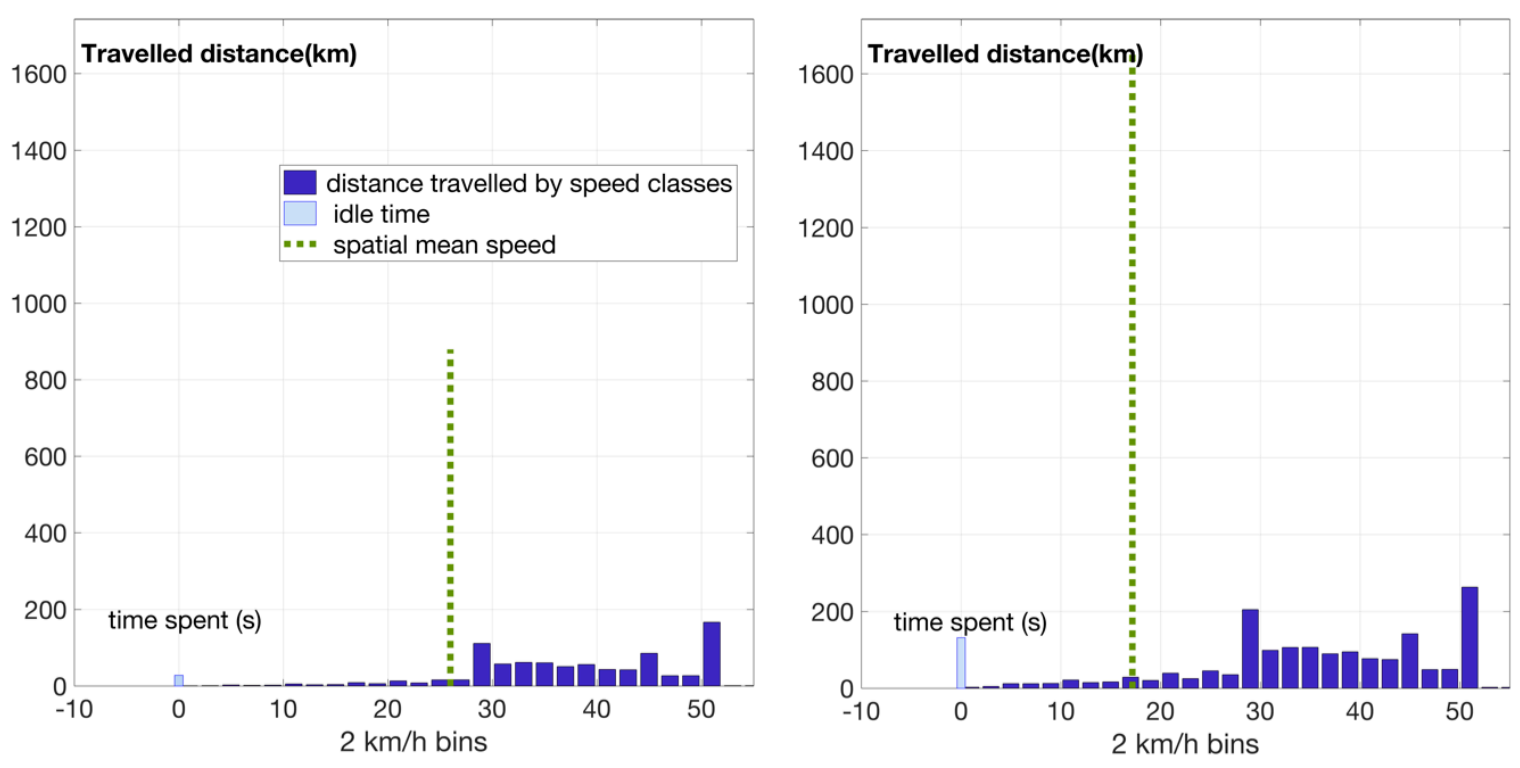

Figure 7 Travel distance per $2 \mathrm{~km} / \mathrm{h}$ speed classes over the network under freeflow (left) and congested (right) conditions

The particular case of idling time can represent from $23 \%$ to $42 \%$ of time spent on network. The PHEM model provided the values of idling emissions for each pollutant and vehicle category. For instance, for passenger cars, idling FC is set at $0.17 \mathrm{~g} / \mathrm{s}$ whereas NOx emissions are set at $0.0011 \mathrm{~g} / \mathrm{s}$.

When considering an average speed as a distribution of instantaneous speeds around this average, a mathematical formulation of the emission curves as a function of the instantaneous speeds is determined using a convolution. However, using this new expression, emissions are always calculated at the scale of a vehicle flow and not at the individual scale. In accordance with the spirit of the COPERT methodology, emission factors are defined for each vehicle category by integrating the fleet distribution within that category. COPERT emissions functions are therefore fitted and transformed into suitable functions with instantaneous speeds. We consider that each mean speed $V$ stands for $a$ range of experimental instantaneous speed distributed in the interval $[V-\alpha ; V+\alpha]$, which follows a uniform distribution $d_{\sigma}$, with $\sigma^{2}=\alpha^{2} / 3$. Thus, the emission associated with a mean speed $V$ can be seen as a mixture of emission levels experimented for the different instantaneous speed classes. The emission functions $\boldsymbol{F}^{k, c}$ depending on mean speed $V$ are rewritten as follows:

$$
\boldsymbol{F}^{k, c}(V)=\int_{V-\alpha}^{V+\alpha} \boldsymbol{G}^{k, c}(w) \cdot \boldsymbol{d}_{\sigma} d w
$$

This formula helps to define the instantaneous emission functions $\boldsymbol{G}^{k, c}$ of interest. Considering that $\boldsymbol{G}^{k, c}$ can be adjusted with a $4^{\text {th }}$ degree polynomial, the first result is that the functions $\boldsymbol{F}^{k, c}$ maintain the same polynomial form.

With $G^{\mathrm{k}, \mathrm{c}}(\mathrm{w})=\mathrm{p}_{4}^{\mathrm{k}, \mathrm{c}} \mathrm{w}^{4}+\mathrm{p}_{3}^{\mathrm{k}, \mathrm{c}} \mathrm{w}^{3}+\mathrm{p}_{2}^{\mathrm{k}, \mathrm{c}} \mathrm{w}^{2}+\mathrm{p}_{1}^{\mathrm{k}, \mathrm{c}} \mathrm{w}+\mathrm{p}_{0}^{\mathrm{k}, \mathrm{c}}$, equation (3) becomes:

$$
\boldsymbol{F}^{k, c}(V)=\int_{V-\alpha}^{V+\alpha}\left(p_{4}^{k, c} w^{4}+p_{3}^{k, c} w^{3}+p_{2}^{k, c} w^{2}+p_{1}^{k, c} w+p_{0}^{k, c}\right) \cdot \frac{1}{2 \alpha} d w
$$




$$
\begin{gathered}
=\frac{1}{2 \alpha}\left[p_{4}^{k, c} \frac{w^{5}}{5}+p_{3}^{k, c} \frac{w^{4}}{4}+p_{2}^{k, c} \frac{w^{3}}{3}+p_{1}^{k, c} \frac{w^{2}}{2}+p_{0}^{k, c} w\right]_{V-\alpha}^{V+\alpha} \\
=p_{4}^{k, c} V^{4}+p_{3}^{k, c} V^{3}+\left(\begin{array}{c}
\left.p_{2}^{k, c}+6 \sigma^{2} p_{4}^{k, c}\right) V^{2}+\left(p_{1}^{k, c}+3 \sigma^{2} p_{3}^{k, c}\right) V+\left(p_{0}^{k, c}+\sigma^{2} p_{2}^{k, c}+\right. \\
\left.9 / 5 \sigma^{4} p_{4}^{k, c}\right)
\end{array}\right.
\end{gathered}
$$

Furthermore, considering $3^{\text {rd }}$ order polynomials, the expression of functions $\boldsymbol{F}^{k, c}$ is the same with a uniform and a normal distribution. With $4^{\text {th }}$ order polynomials, the new curve is formulated with both distributions as a fourth order polynomial but the coefficients differ. In order to provide a clear presentation of the concept, here we explain only the formulation for $a 4^{\text {th }}$ order polynomial and a uniform distribution.

The functions $\boldsymbol{F}^{k, c}$ are fitted on existing COPERT curves for each vehicle class $c$ and each pollutant $k$. The fitting process provides numerical values of polynomial coefficients and $\alpha$. The latter is estimated between 8 and 13. This is in accordance with the speed standard deviation of urban driving cycles.

The $\boldsymbol{G}^{k, c}$ functions are then derived from the coefficients obtained. These functions, depicted for FC and NOx emissions in Figure 8, resemble the initial functions, but are slightly lower in the speed range of interest.
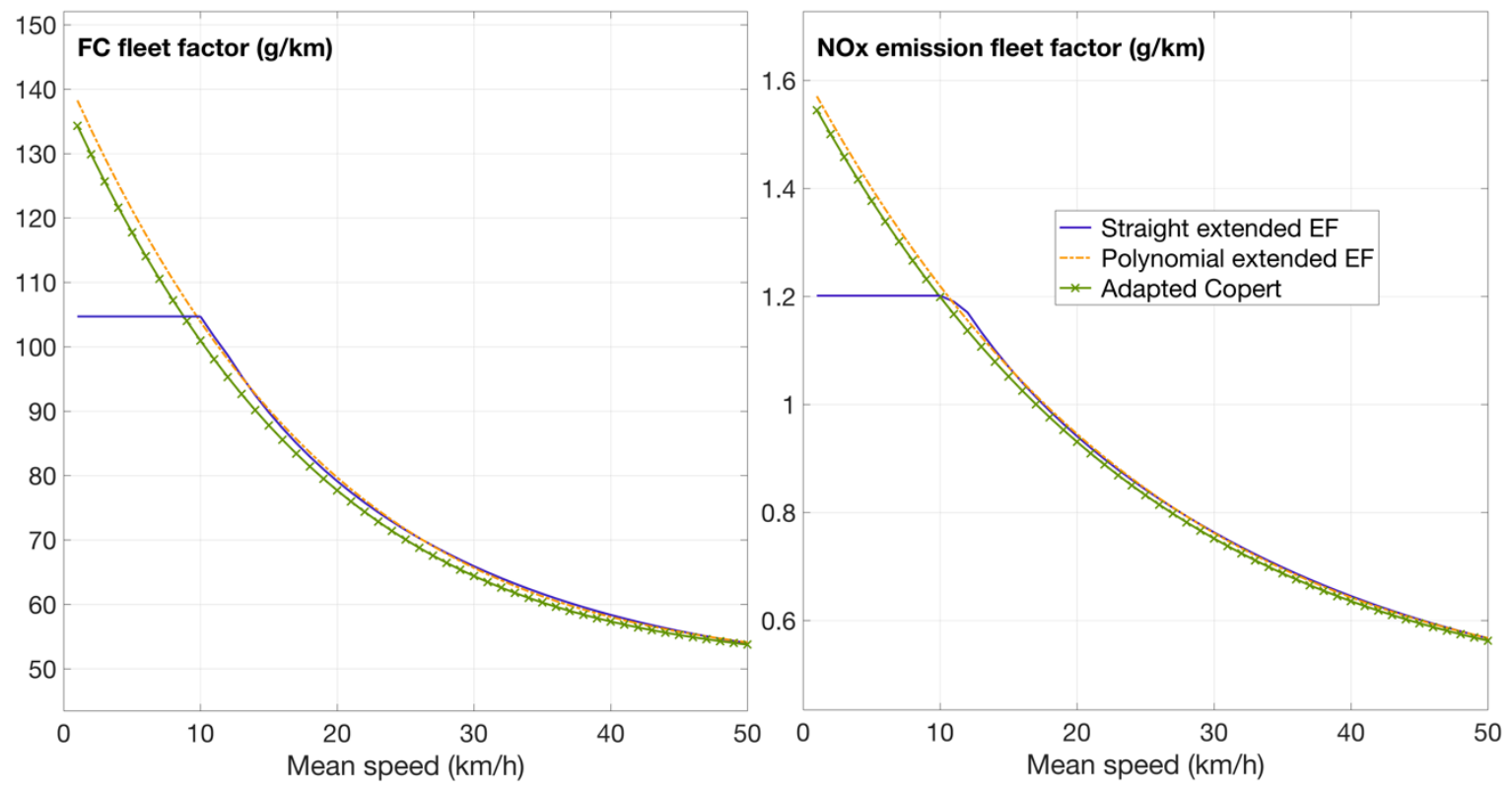

Figure 8 Adapted COPERT emission functions: COPERT emission functions with straight extension for low speed, with the fitted COPERT emission functions permitting polynomial extension and the emission functions adapted to instantaneous speed (left: FC estimate; right: NOx estimate)

The adapted COPERT emission functions will be further coupled to simulated traffic data in terms of time spent per speed classes. This innovative way of implementing emission functions is derived from equation (1):

$$
E^{k, c}=\sum_{i} \mathrm{~T}_{i}^{c} \cdot G^{k, c}\left(V^{i}\right)
$$


with $G^{k, c}$ the "instantaneous" unitary emission factor $(\mathrm{g} / \mathrm{s})$ of pollutant $k$ and vehicle class $c$

$T^{c}$ the total time spent by vehicle class $c(\mathrm{~s})$

$V^{i}$ the speed characterizing the $\mathrm{i}^{\text {th }}$ speed class $(\mathrm{km} / \mathrm{h})$

Here, $2 \mathrm{~km} / \mathrm{h}$ speed classes were selected and $1 \mathrm{~s}$ vehicle speeds were reformulated with the total time spent in each speed class. The corresponding network emissions are analyzed in section 4.2 .

\section{Sensitivity of COPERT to the speed definitions for emissions calculated at the network scale}

\subsection{Sensitivity to speed definition}

The FC and NOx emissions are calculated at each road segment every 6 min by formula (1), and then summed to observe the impact of speed definition on the emissions calculated over the network. The calculated emissions obtained with the spatial mean speed serve as references, as this speed definition is the most accurate that can be encountered.

Figure 9 represents the network emissions for each 6 min period, obtained with COPERT (straight extension for the lowest speeds) and the various speed definitions. Degraded speed definitions (speed limit and punctual loops) lead globally to underestimated emissions. The discrepancies between the calculated emissions also depend on the period, and reach their maximum value during congestion (grey area).

Figure 96 min fuel consumption (left) and NOx emissions (right) over the network during the morning peak for the various speed definitions.

At the network scale, the positions of the virtual loops do not have a significant impact on
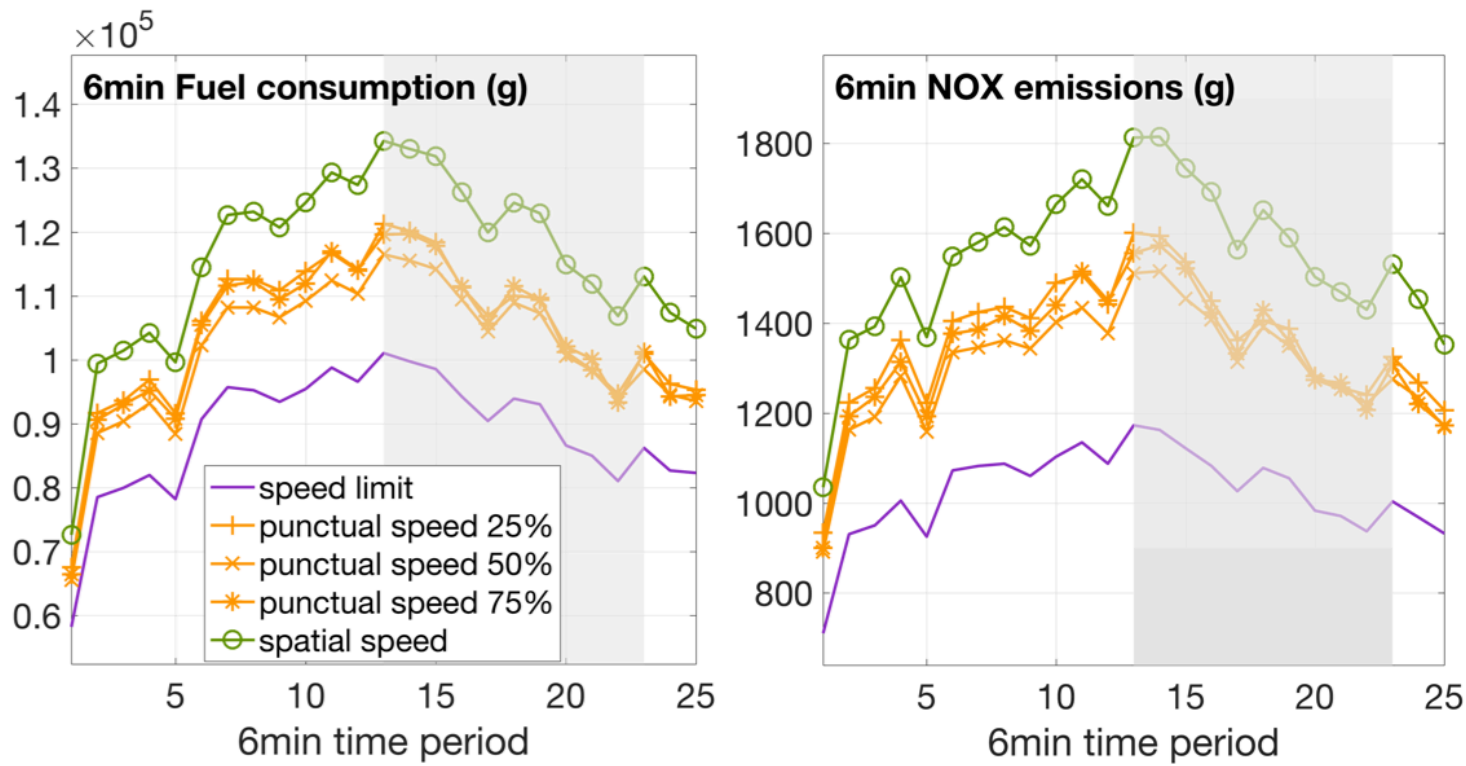

the estimated emissions. Thus, only virtual loops positioned in the middle of the road segment (the 50\% loop) are kept in the rest of this article. Using the loop detectors to 
estimate mean speeds introduces discrepancies on the global emissions at the 6 min period scale that range from $-9.7 \%$ to $-13.4 \%$ for $\mathrm{FC}$, and from $-13.5 \%$ to $-17.1 \%$ for NOx, compared with the global emissions obtained with the spatial mean speed definition. Using the speed limit to estimate mean speeds introduces an emission bias at the 6 min period scale that ranges from $-19.8 \%$ to $-25.3 \%$ for FC, and from $-30.7 \%$ to $-36.0 \%$ for NOx.
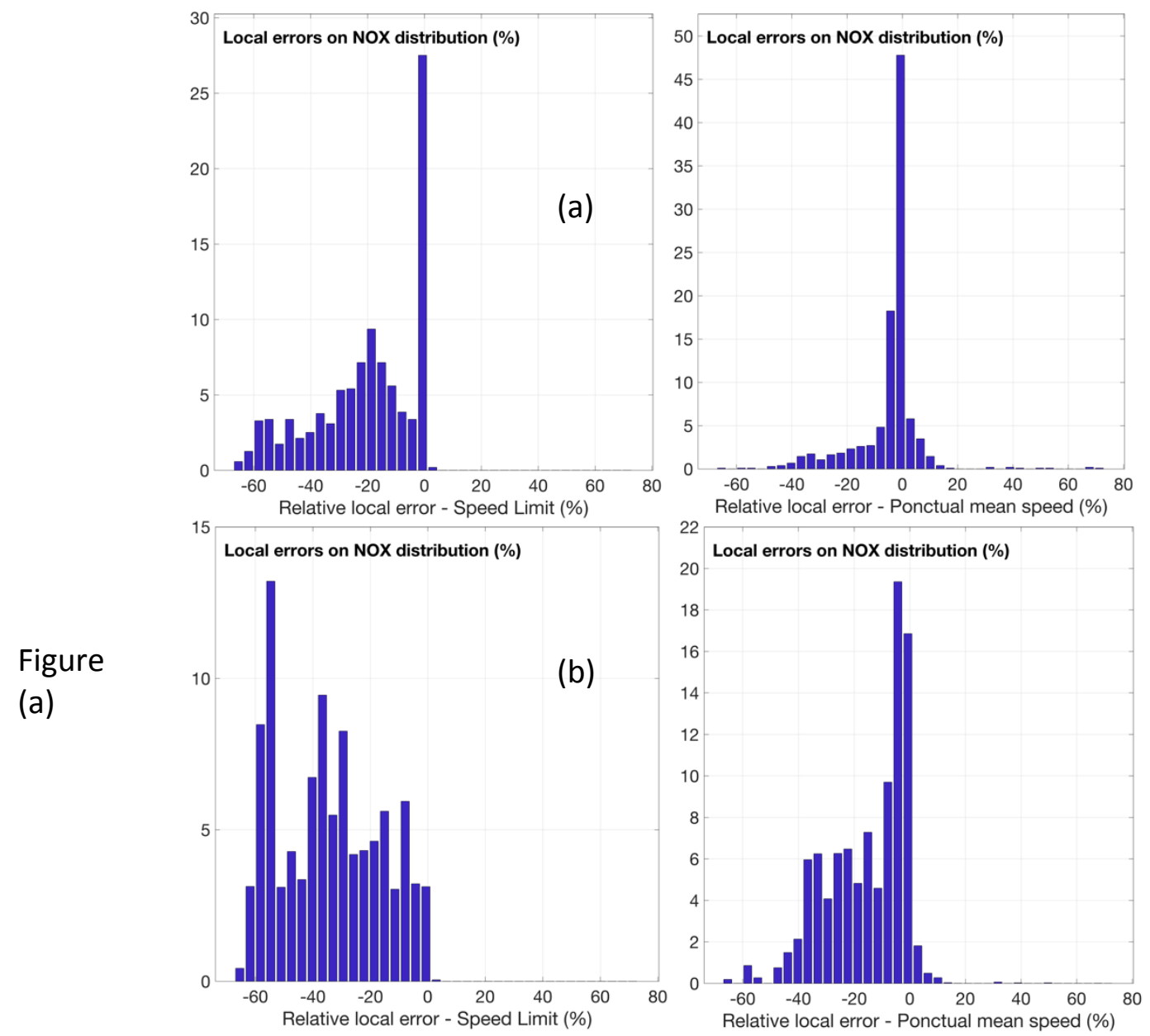

Figure 10

(a) Distribution of local relative errors on NOx for a congested period associated with a degraded speed definition: Speed limit (left); Punctual mean speed (right) - in terms of \% of road segments.

(b) Distribution of local relative errors on NOx for a congested period associated to a degraded definition of speed: Speed limit (left); Punctual mean speed (right) - in terms of \% of the total emissions

represents the spatial distribution of the discrepancies on emissions calculated at the road segment scale for a specific congested period, according to the speed definition. The local errors are higher than the global ones, especially under congestion. For NOx emissions, the mean relative error using the speed limit ranges locally from $-67.2 \%$ to $+4.6 \%$, and from $64.5 \%$ to $73.0 \%$, using the punctual mean speed.

The punctual mean speed definition yields an almost null bias for $47.8 \%$ of the road segments for this period. Indeed, almost a third of these road segments do not significantly contribute to the network emissions. This can be explained by the heterogeneity of the network (in terms of geometry and/or traffic). More specifically, Figure 10 (b) represents the spatial distribution in terms of percentage of total emissions. Using a speed limit as the mean speed for emission estimation leads to a nearly null local error in $28 \%$ of the road segments, with represents around $3 \%$ of the total emissions. On the 
contrary, when it comes to small sets of road segments associated with huge local gaps (around $-60 \%$ ), these can contribute to $13 \%$ of the total emissions.

The spatial analysis reveals that locally the bias can be dramatically higher. However, it also shows that the necessary accuracy on mean speed can be considered in terms of emission stakes and is not homogeneous over the road segments. For further analyses, the mean speed definition chosen will be the spatial mean speed.

\subsection{Sensitivity to the COPERT adaptations}

\subsubsection{Reference scenario}

The COPERT adaptations proposed in section 3.2 are compared in this section for emissions based on the vehicle trajectories provided by the dynamic traffic simulation. Figure 11 shows the discrepancies in emissions calculated over the network for the three COPERT adaptations for free flow and congested periods (grey area).
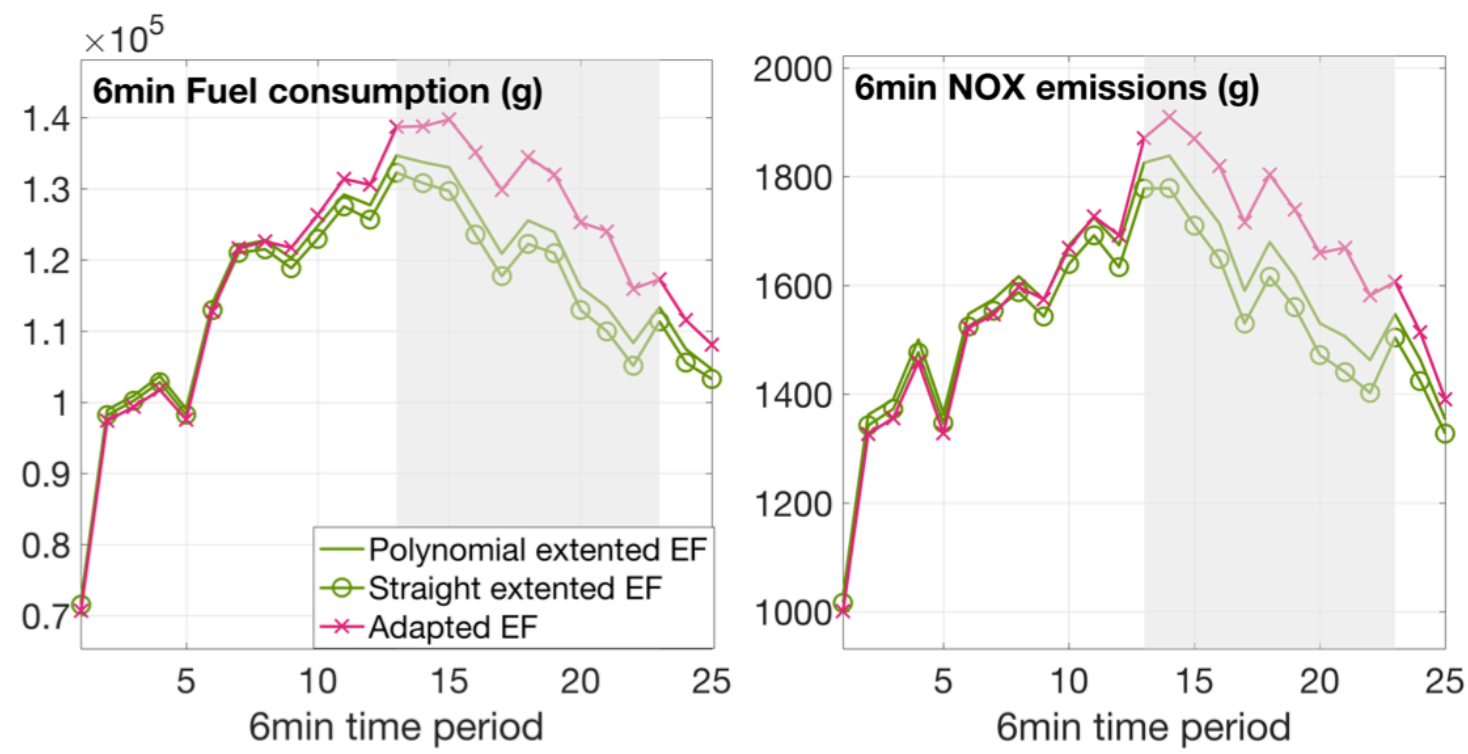

Figure 11 COPERT network FC (left) and NOx emissions (right) evaluated thanks using three adapted emission functions (see section 3.2).

Considering the mean speed approach, using a polynomial extension of COPERT emission functions implicitly results in integrating surplus emissions associated with very low speeds. This is confirmed at the network level: FC (and NOx emission) is therefore lightly overestimated, around $1.7 \%$ (2.6\% for NOx) and at most $3 \%$ ( $4.6 \%$ for NOx), compared with the straight extension of emission functions that serve as references. It is interesting to note that these two strategies have little impact on total emissions/consumption.

On the other hand, using adapted COPERT emission functions introduces a slight underestimation in free flow conditions and an overestimation compared with the straight extension of emission curves. This approach, treating traffic information as time spent by instantaneous speed classes, results in discrepancies at the network scale that range from - 
$1.1 \%$ to $12.8 \%$ for FC (from $-1.5 \%$ to $15.9 \%$ for NOx emissions), that is to say $4.8 \%$ (5.4\% for NOx) for the whole period of 2.5 hours.

\subsubsection{Increased demand scenario}

A congested scenario is implemented, with a $30 \%$ increase in demand, to highlight the discrepancy between the models under congestion. In these conditions, the gaps associated with the use of polynomial extended COPERT emission functions (vs straight extended EF), are slightly accentuated and reach a maximum of $7 \%$ for FC and $8.8 \%$ for NOx emissions. Thus, the discrepancies between mean speed and speed distribution approaches are also increased (from $-0.8 \%$ to $43.2 \%$ for FC and from $-1.3 \%$ to $45.2 \%$ for NOx emission). The total gap for the whole period reaches a $15.3 \%$ discrepancy for the FC estimate and a $15.2 \%$ discrepancy for NOx emissions.

The gap between the two approaches is revealed in Figure 13 (speed distribution versus mean speed) by comparing the NOx emission contribution of each speed class and both
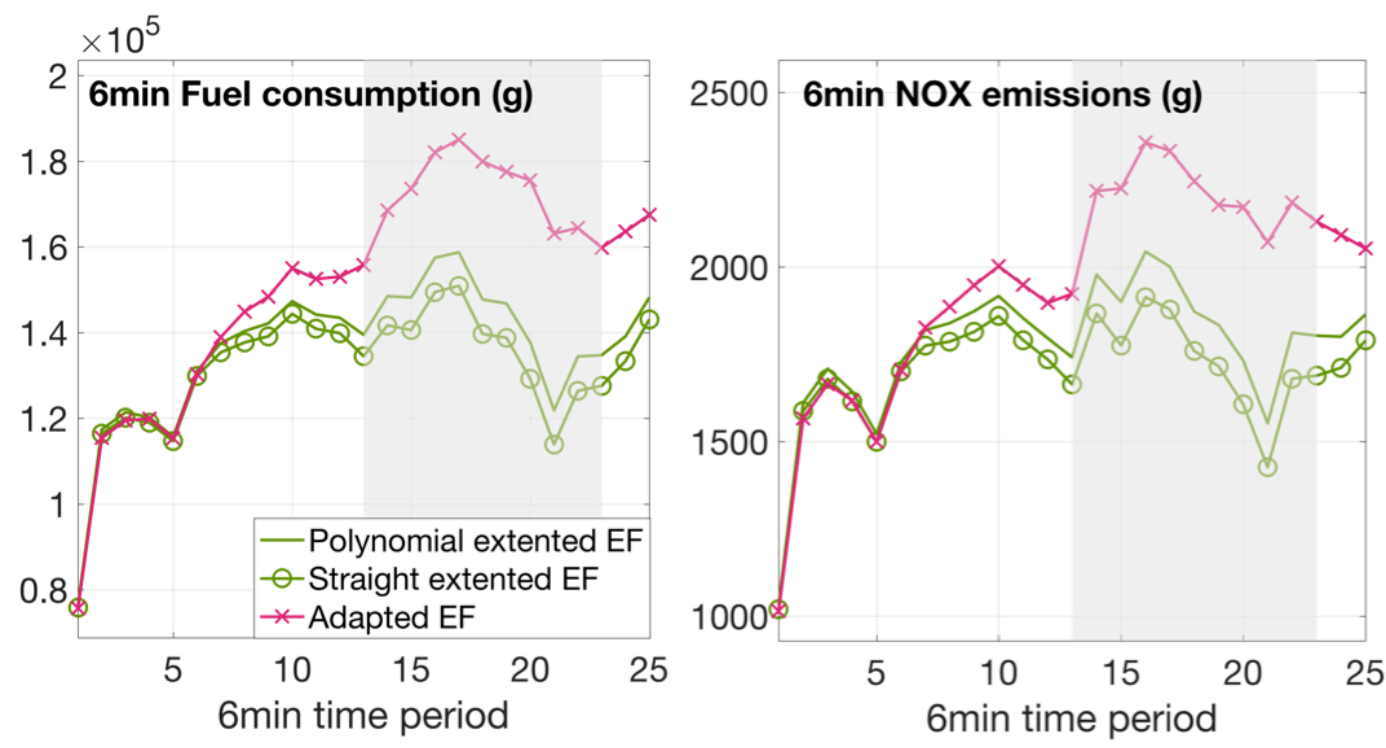

Figure 12 COPERT network FC (left) and NOx emissions (right) evaluated using three adapted emission functions for the "increased demand" scenario.

scenarios. In Figure 13.a, the $2 \mathrm{~km} / \mathrm{h}$ bins are defined on instantaneous speed and integrated in the calculation as time spent in the speed class considered. In Figure 13.b, the $2 \mathrm{~km} / \mathrm{h}$ bins are defined for a 6 min mean speed and integrated in the calculation as distance travelled at the speed class considered. These distributions show the major contribution of emission associated with idling time, which is treated individually in the first case but mixed in the 6 min mean fleet speed. This effect is even more significant for the increased demand scenario, where the vehicles under congestion are stopped for $37.6 \%$ of the time, versus $26.2 \%$ for the reference scenario. 

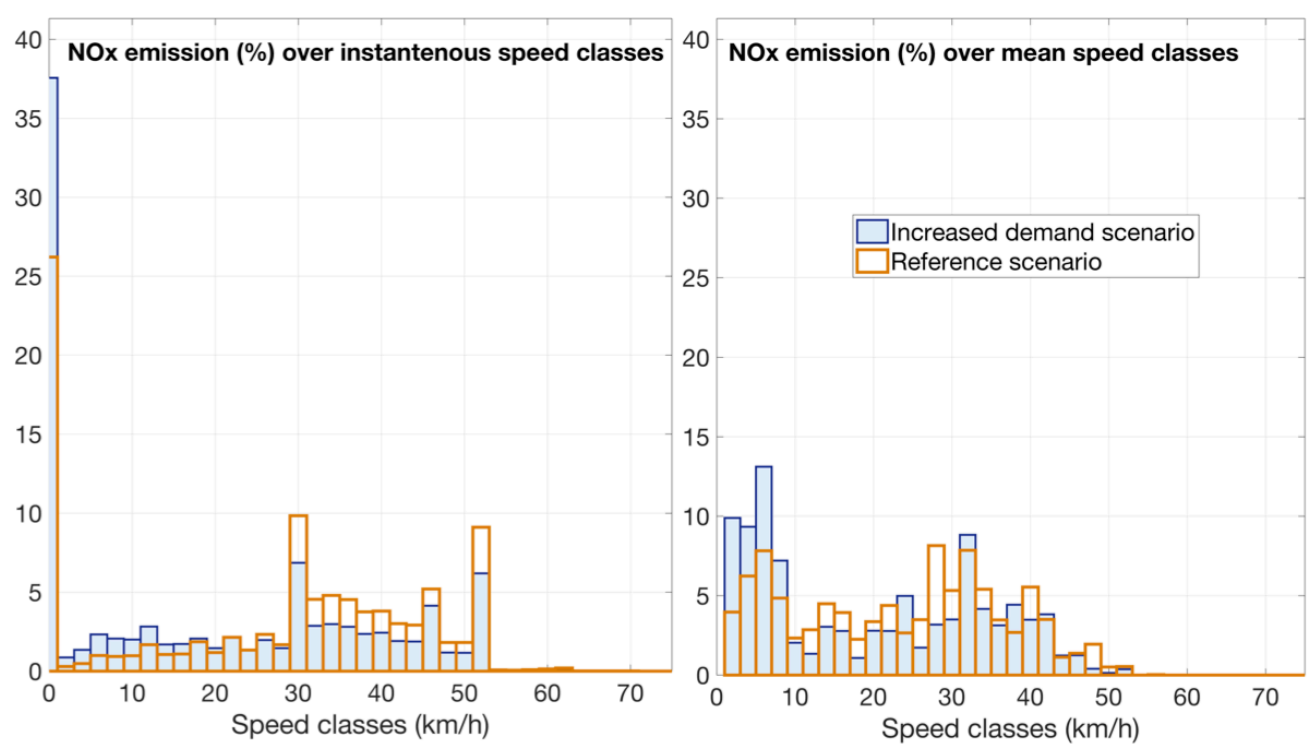

Figure 13 Contribution to NOx emission by speed classes in terms of instantaneous speed or 6 min mean speed for a 6 mincongested period.

The use of speed distributions provided by the dynamic traffic simulation leads to higher FC and NOx emissions, especially during congested periods (grey area). This traffic data treatment is certainly associated with better integration of low speeds and speed variability. These traffic conditions also correspond to the most emissive conditions. This specific trafficemission coupling seems to evaluate real emission conditions more precisely at the network scale, although this is not validated experimentally here. In the absence of validation, the emission levels could be compared to emissions evaluated using an instantaneous emission model such as PHEM.

\section{Comparison of emissions models}

This section is devoted to emission calculations at the road segment scale, using the PHEM and COPERT models. The general objective of this paper is to use a traffic microsimulation to evaluate pollutant emissions and to analyze the differences found between the implementation of different methodologies.

The hypothesis tested is that the aggregate COPERT model, based on average speed, is not capable of integrating all the speed variability, which is higher during congestion. On the contrary, we assume that the PHEM model, which relies on vehicle kinematics, is able to integrate these typical phenomena. The differences observed are therefore interpreted in relation to traffic dynamics, although the absolute differences between the models may be due to other origins. This is why the analysis will not conclude on the best performance of one model compared to another, but rather aim to assess their sensitivity to traffic dynamics. 


\subsection{PHEM emissions}

As the microsimulation provides very detailed information for each vehicle (1s trajectories), the temptation is great to use an emission model able to maintain this level of detail. Despite the huge amount of data to be implemented (associated with approximately 2 hours calculation for one run), the traffic data is compatible with the input data of the PHEM modal emissions model .
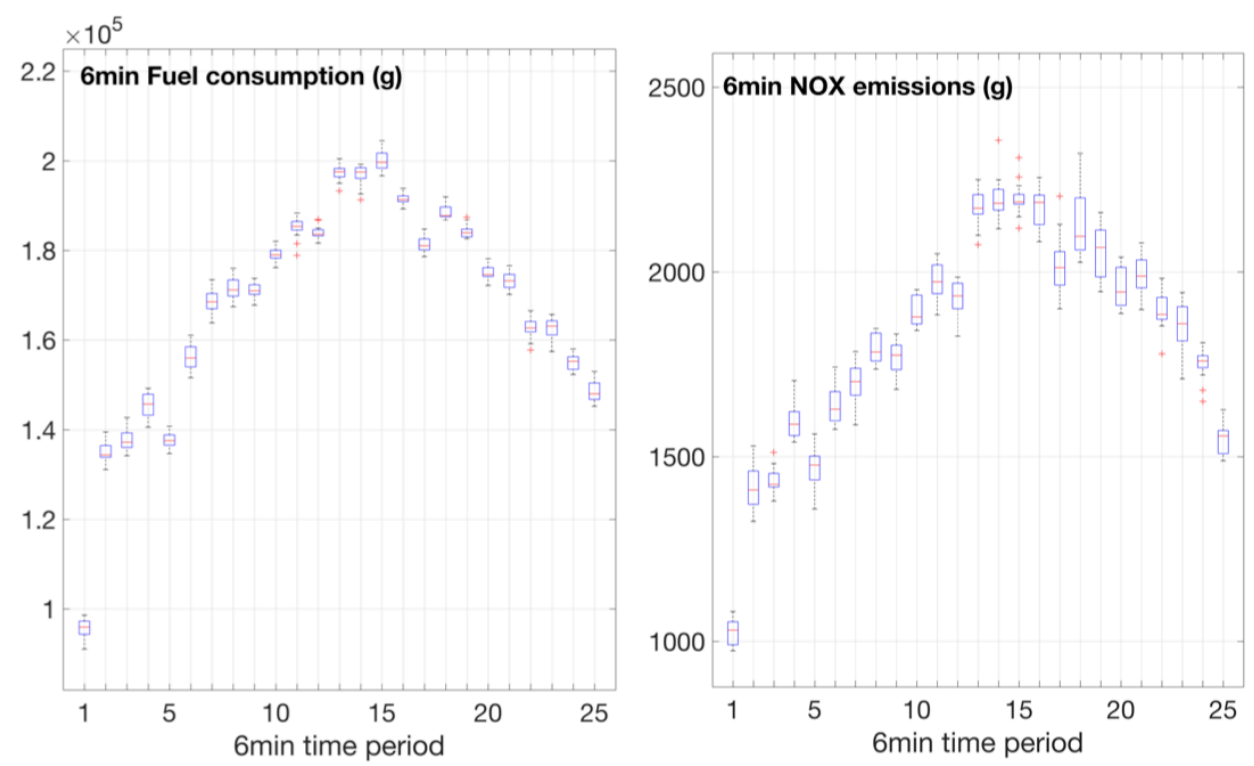

Figure 14 Dynamic network PHEM emissions resulting from 15 replications.

Figure 14 represents the time evolution of the fuel consumption (and NOx emissions) over the network obtained with PHEM. With no information on vehicle technology except for vehicle classes, the model stochastically associates a technology with a particular vehicle of the class considered (Passenger cars, Light Duty Vehicles, Buses or Heavy Duty Vehicle), conforming to the input fleet composition described in section 2.2. The boxplot shown in the figure is associated with PHEM emission values over 15 replications. The first observation is that the stochastic fleet definition not only impacts local emissions but also network emissions. The global relative gaps over time periods range from $-5.0 \%$ to $3.7 \%$ for fuel consumption, and from $-8.0 \%$ to $9.2 \%$ for NOx emissions.

For the following analysis, the emission evaluated with PHEM will be represented as the mean value of the replications for each 6 min time period.

\subsection{PHEM and COPERT emissions}

Finally, three modeling chains, starting from the same traffic microsimulation, were compared at the network scale in terms of fuel consumption and NOx emissions. Individual traffic trajectories were coupled with PHEM, whereas COPERT was implemented with 
aggregated traffic variables (spatial mean speed) and speed distribution (see section 3.2). All the environmental assessments were produced for a given fleet transcribed in the emissions models.

At the driving cycle scale, PHEM overestimates overall consumption compared to COPERT in congested conditions, but the trend is less marked for NOx emissions. The issue of model consistency encountered by emission modelers is not addressed in this paper. The authors deliberately chose not to artificially modify the parameters of the emission models to make them consistent. The analysis below does not focus on the nominal values proposed by the tools but on their evolution according to traffic conditions. To do this, the emissions normalized by the average value over the period were plotted for both scenarios without involving the inherent differences due to the model versions in use (see Figures $16 \& 18$ ).
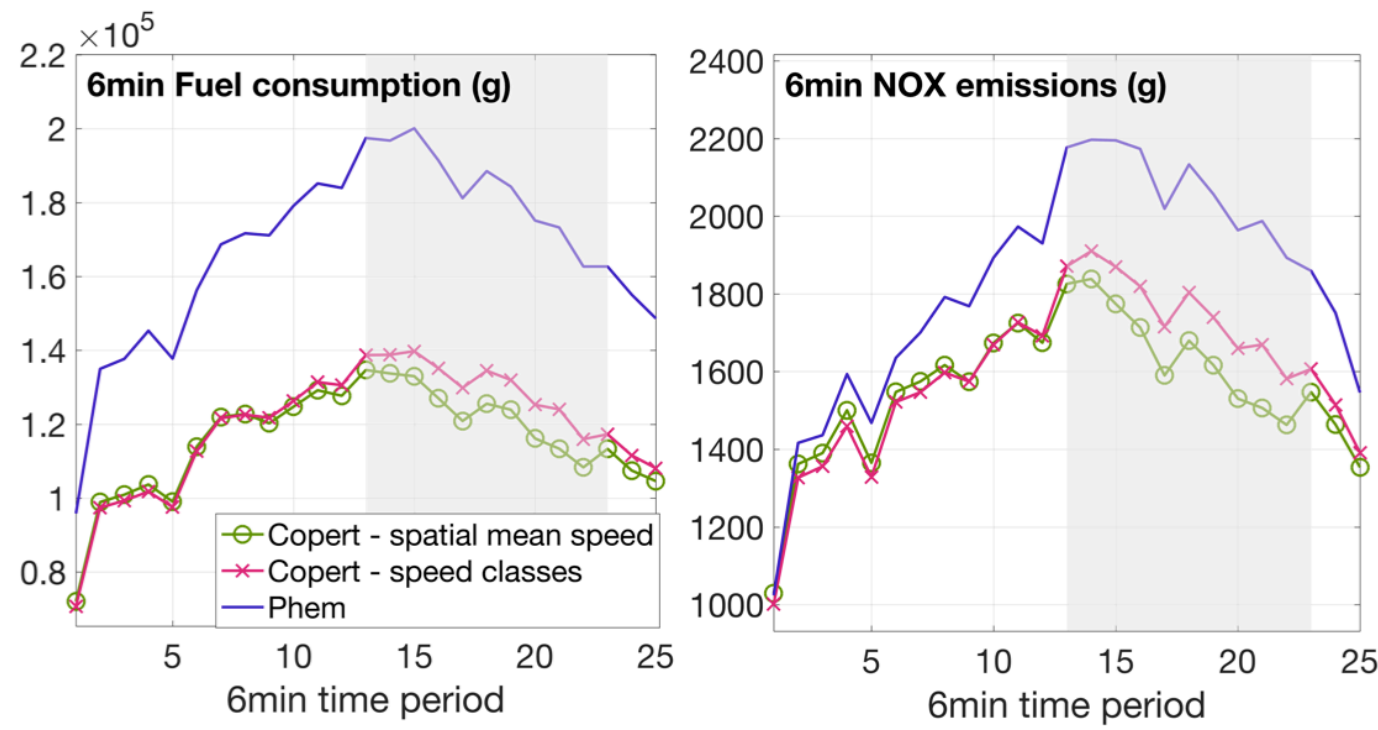

Figure 15 Comparison of network FC (left) and NOx emissions (right) with three modeling chains for the reference scenario

As shown in Figure 15, the PHEM modal emission model obtains higher emission levels, especially for congestion periods. The gap between COPERT emissions (with spatial mean speed) compared to PHEM emissions is quantified: the relative deviations reach $-34.6 \%$ for fuel consumption (-24.2\% for NOx emissions). Using the adapted COPERT emission functions reduced the maximum relative discrepancies to $-30.1 \%$ for fuel consumption (-16.5\% for NOx emissions). This means that the result is highly dependent on the modeling chain. However, to overcome version-related deviations, the emission values were compared by model between fluid and congested periods for the two scenarios and between both scenarios (see Table 1). 

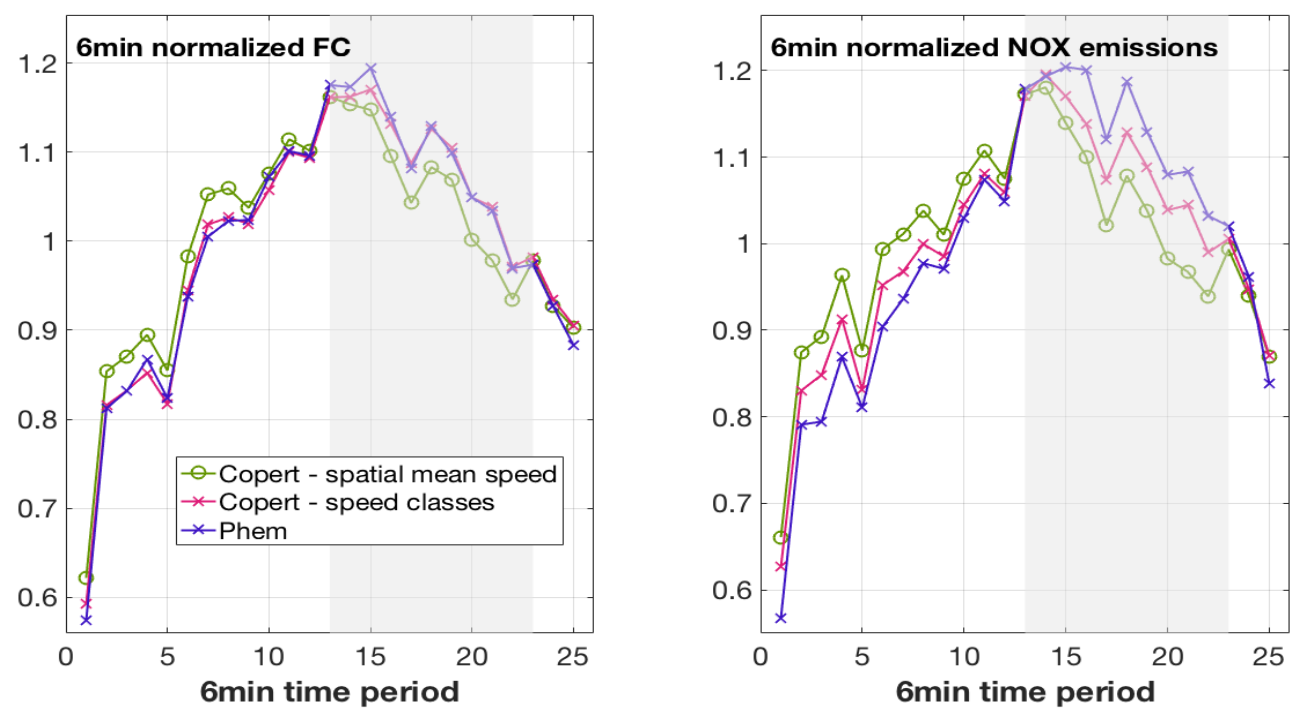

Figure 16 Comparison of normalized network FC (left) and NOx emissions (right) with three modeling chains for the reference scenario.

Figure 1 shows that all the models follow the overall traffic pattern over the period considered. However, it reveals that in a free-flowing situation, the average-speed approach tends to overestimate NOx emissions/consumption, whereas in congested conditions, it tends to underestimate them because it does not include the effects of congestion.

These differences have been quantified comparing the emission on $\left(E_{o n}\right)$ and off $\left(E_{o f f}\right)$ peak for both scenarios and drawing the comparison between scenario 1 and 2, distinguished by the congestion rate:

$$
\begin{gathered}
\delta=\left(E_{\text {on }}-E_{\text {off }}\right) / E_{\text {total }} \times 100 \\
\Delta=\left(E_{\text {tot } 1}-E_{\text {tot } 2}\right) /\left(E_{\text {tot } 1}+E_{\text {tot } 2}\right) \times 100
\end{gathered}
$$

These indicators should be read as follows: the higher the value, the more the methodology integrates the traffic dynamics.

Table 1 Performance indicators (\%) reflecting the integration of traffic dynamics.

\begin{tabular}{|c|c|c|c|}
\hline NOx & PHEM & $\begin{array}{c}\text { COPERT - speed } \\
\text { classes }\end{array}$ & $\begin{array}{c}\text { COPERT - mean } \\
\text { speed }\end{array}$ \\
\hline$\delta_{1}$ & 13.8 & 10.8 & 6.7 \\
\hline$\delta_{2}$ & 21.0 & 15.5 & 6.3 \\
\hline$\Delta$ & 13.9 & 9.9 & 5.6 \\
\hline
\end{tabular}




\begin{tabular}{|c|c|c|c|}
\hline FC & PHEM & $\begin{array}{c}\text { COPERT - speed } \\
\text { classes }\end{array}$ & $\begin{array}{c}\text { COPERT - mean } \\
\text { speed }\end{array}$ \\
\hline$\delta_{1}$ & 10.7 & 10.6 & 7.3 \\
\hline$\delta_{2}$ & 17.0 & 17.0 & 8.0 \\
\hline$\Delta$ & 13.1 & 11.8 & 7.2 \\
\hline
\end{tabular}

The same conclusion with enhanced effects can be observed with the increased demand scenario Figure 17 and 18). Comparing COPERT to PHEM emissions, the relative deviations reach $-46.8 \%$ for fuel consumption (-41.5\% for NOx emissions). Using adapted COPERT emission functions reduces the maximum relative discrepancies to $-32.1 \%$ for fuel consumption (-24.4\% for NOx emissions).

Once again, this comparison says nothing about the more realistic emission level and these
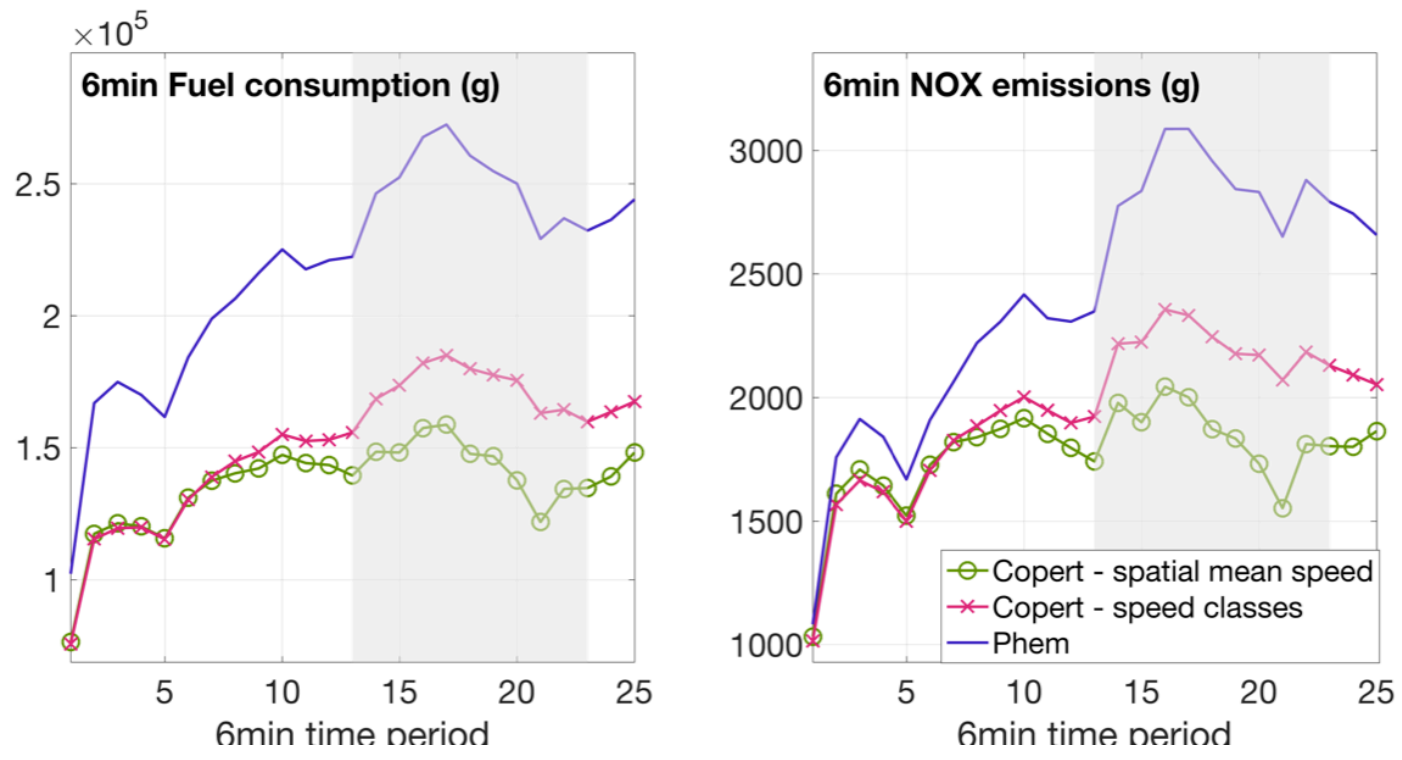

Figure 17 Comparison of network FC (left) and NOx emissions (right) with three modeling chains for the increased demand scenario.

results cannot be seen as a recommendation for using one modeling chain rather than another. The purpose is to exhibit the potential deviations induced by different treatments of the same traffic microsimulation. 

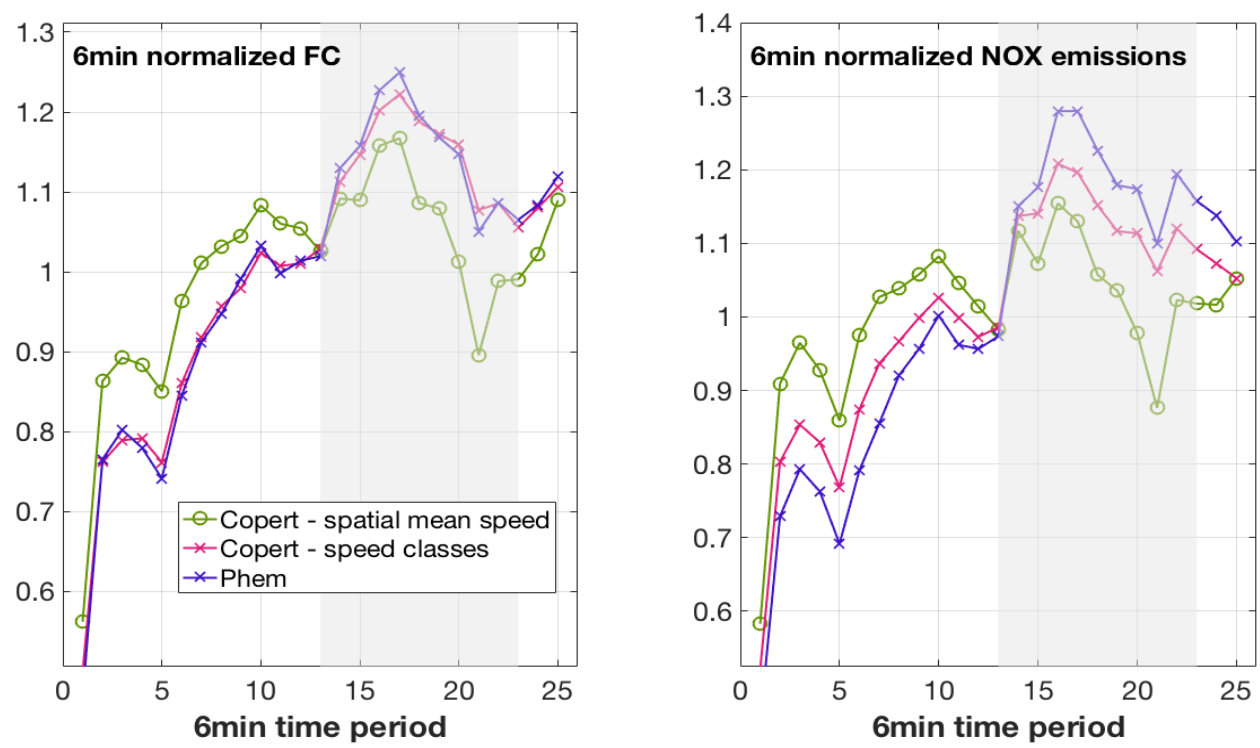

Figure 18 Comparison of normalized network FC (left) and NOx emissions (right) with three modeling chains for the increased demand scenario.

\section{Discussion}

In a context where transportation managers are urged to take the environmental impact of road traffic into account, the challenge is to provide an accurate dynamical estimation of the network emissions. Indeed, to qualify the existing situation or traffic regulation measures, officials are interested in accurate environmental evaluations. To do this, evaluation methods, even at the city scale, cannot ignore traffic dynamics, that is to say the congestion phenomenon.

This point was stressed in particular in this article: traffic microsimulation provides a fine representation of vehicle kinematics, which is relevant for emission calculations. Indeed, when comparing emission calculations, each discrepancy observed, even at the network scale, depended on traffic conditions and was considerably greater during congestion.

When implementing emission calculations from vehicle trajectories, an instantaneous model, such as PHEM, seems to be more efficient. The strategy is definitely time-consuming but still affordable in terms of the amount of data processed. Nevertheless, this article specified the imprecision due to the fact that we do not know the real fleet composition: this can induce a non-negligible deviation, even at the network scale. With the simulated traffic data, the absolute global relative error can reach $5.0 \%$ for fuel consumption and $9.2 \%$ for NOx emissions.

Regarding aggregating emission models, such as COPERT, the first step is to define the useful aggregated traffic variables. This article specifically underlined the need for caution regarding the mean speed definition. The gap associated with a degraded definition was quantified. In the case of missing information, the road segment limit speed can occasionally be used to evaluate emissions, leading to a critical bias (-25\% for FC, $-30 \%$ for NOx). 
Finally, another approach was proposed, improving traffic representation: traffic conditions were no longer synthesized with a mean speed but with a speed distribution. A theoretical reflection was proposed to adapt the COPERT emission functions to this input information. Consequently, the evaluation led to a higher emission value. The performance indicators were more or less doubled compared to a classical implementation and revealed that the integration of traffic dynamics was successful. This modeling chain appeared efficient at the urban scale in congested conditions.

This article focused on comparing emission models but cannot conclude on favoring one modeling chain over another. Its contribution lies in the description of the requisite traffic dynamics: congested periods should be characterized carefully. However, the issue of validation remains to be addressed. It would be interesting to compare these results to measurements, such as ambient concentrations, to obtain an idea of the range of real emissions over the network.

\section{Acknowledgments}

This work was performed in the framework of the Trafipollu research project funded by the National Research Agency under contract no. ANR-12-VBDU-0002-01.

\section{References}

Ahn, K., Rakha, H., 2009. A field evaluation case study of the environmental and energy impacts of traffic calming. Transp. Res. Part D Transp. Environ. 14, 411-424. https://doi.org/10.1016/j.trd.2009.01.007

André, M., Hammarström, U., 2000. Driving speeds in Europe for pollutant emissions estimation. Transp. Res. Part D Transp. Environ. 5, 321-335. https://doi.org/10.1016/S1361-9209(00)00002-X

André, M., Rapone, M., 2009. Analysis and modelling of the pollutant emissions from European cars regarding the driving characteristics and test cycles. Atmos. Environ. 43, 986-995. https://doi.org/10.1016/j.atmosenv.2008.03.013

Borge, R., de Miguel, I., de la Paz, D., Lumbreras, J., Pérez, J., Rodríguez, E., 2012. Comparison of road traffic emission models in Madrid (Spain). Atmos. Environ. 62, 461471. https://doi.org/10.1016/j.atmosenv.2012.08.073

Chen, K., Yu, L., 2007. Microscopic Traffic-Emission Simulation and Case Study for Evaluation of Traffic Control Strategies. J. Transp. Syst. Eng. Inf. Technol. 7, 93-99. https://doi.org/10.1016/S1570-6672(07)60011-7

Chevallier, E., Leclercq, L., 2007. A macroscopic theory for unsignalized intersections. Transp. Res. Part B Methodol. 41, 1139-1150. https://doi.org/10.1016/j.trb.2007.05.003

De Vlieger, I., De Keukeleere, D., Kretzschmar, J.., 2000. Environmental effects of driving behaviour and congestion related to passenger cars. Atmos. Environ. 34, 4649-4655. https://doi.org/10.1016/S1352-2310(00)00217-X

Edie, L.C., 1965. Discussion of traffic stream measurements and definitions., in: 2nd International Symposium on the Theory of Traffic Flow. pp. 8-20.

Ericsson, E., 2001. Independent driving pattern factors and their influence on fuel-use and exhaust emission factors. Transp. Res. Part D Transp. Environ. 6, 325-345. https://doi.org/10.1016/S1361-9209(01)00003-7 
Fallah Shorshani, M., André, M., Bonhomme, C., Seigneur, C., 2015. Modelling chain for the effect of road traffic on air and water quality: Techniques, current status and future prospects. Environ. Model. Softw. 64, 102-123. https://doi.org/10.1016/j.envsoft.2014.11.020

Frey, H.C., Zhang, K., Rouphail, N.M., 2010. Vehicle-Specific Emissions Modeling Based upon on-Road Measurements. Environ. Sci. Technol. 44, 3594-3600. https://doi.org/10.1021/es902835h

Hansen, J.Q., Winther, M., Sorenson, S.C., 1995. The influence of driving patterns on petrol passenger car emissions. Sci. Total Environ. 169, 129-139. https://doi.org/10.1016/0048-9697(95)04641-D

Hausberger, S., 2003. Simulation of Real World Vehicle Exhaust Emissions., VKM-THD Mitteilungen; Heft/Vol 82; Verlag der Technischen Universität Graz, ISBN 3-901351-744.

Hausberger, S., Rodler, J., Sturm, P., Rexeis, M., 2003. Emission factors for heavy-duty vehicles and validation by tunnel measurements. Atmos. Environ. 37, 5237-5245. https://doi.org/10.1016/j.atmosenv.2003.05.002

Jie, L., Van Zuylen, H., Chen, Y., Viti, F., Wilmink, I., 2013. Calibration of a microscopic simulation model for emission calculation. Transp. Res. Part C Emerg. Technol. 31, 172184. https://doi.org/10.1016/j.trc.2012.04.008

Jiménez-palacios, J.L., 1999. Understanding and Quantifying Motor Vehicle Emissions with Vehicle Specific Power and TILDAS Remote Sensing.

Joumard, R., André, M., Vidon, R., Tassel, P., Pruvost, C., André, M., Vidon, R., Tassel, P., Pruvost, C., 2000. Infuence of driving cycles on unit emissions from passenger cars. Atmos. Environ. 34, 4621-4628. https://doi.org/10.1016/S1352-2310(00)00118-7

Laval, J.A., Leclercq, L., 2008. Microscopic modeling of the relaxation phenomenon using a macroscopic lane-changing model. Transp. Res. Part B Methodol. 42, 511-522. https://doi.org/10.1016/j.trb.2007.10.004

Leclercq, L., 2007a. Hybrid approaches to the solutions of the "Lighthill-Whitham-Richards" model. Transp. Res. Part B Methodol. 41, 701-709. https://doi.org/10.1016/j.trb.2006.11.004

Leclercq, L., 2007b. Bounded acceleration close to fixed and moving bottlenecks. Transp. Res. Part B Methodol. 41, 309-319. https://doi.org/10.1016/j.trb.2006.05.001

Lu, X.C., 2016. Transportation Research Board Annual Meeting and Publication in the Transportation Research Record Washington, D.C., January, 2012 1-17.

Ma, H., Xie, H., Huang, D., Xiong, S., 2015. Effects of driving style on the fuel consumption of city buses under different road conditions and vehicle masses. Transp. Res. Part D Transp. Environ. 41, 205-216. https://doi.org/10.1016/j.trd.2015.10.003

Madireddy, M., De Coensel, B., Can, A., Degraeuwe, B., Beusen, B., De Vlieger, I., Botteldooren, D., 2011. Assessment of the impact of speed limit reduction and traffic signal coordination on vehicle emissions using an integrated approach. Transp. Res. Part D Transp. Environ. 16, 504-508. https://doi.org/10.1016/j.trd.2011.06.001

Ntziachristos, L., Gkatzoflias, D., Kouridis, C., 2009. COPERT: A European Road Transport Emission Inventory Model. Inf. Technol. Environ. Eng. https://doi.org/10.1007/978-3540-88351-7

Pitsiava-Latinopoulou, M., Melios, G., Gavanas, N., Tsakalidis, A., Aggelakakis, A., Kouridis, C., 2014. Development of a system of environmental and energy consumption data for urban road traffic, Pilot application in Thessaloniki, Greece. Transp. Res. Arena 2014 - 
Transp. Solut. From Res. to Deploy. - Innov. Mobility, Mobilise Innov. Paris, Fr. 14 - 17 April 2014.

Qu, L., Li, M., Chen, D., Lu, K., Jin, T., Xu, X., 2015. Multivariate analysis between driving condition and vehicle emission for light duty gasoline vehicles during rush hours. Atmos. Environ. 110, 103-110. https://doi.org/10.1016/j.atmosenv.2015.03.038

Samaras, C., Ntziachristos, L., Samaras, Z., 2014. COPERT Micro: a tool to calculate the vehicle emissions in urban areas. Transp. Res. Arena 201410.

Samaras, C., Tsokolis, D., Toffolo, S., Magra, G., Ntziachristos, L., Samaras, Z., 2017. Improving fuel consumption and CO2emissions calculations in urban areas by coupling a dynamic micro traffic model with an instantaneous emissions model. Transp. Res. Part D Transp. Environ. https://doi.org/10.1016/j.trd.2017.10.016

Shaughnessy, W.J., Venigalla, M.M., Trump, D., 2015. Health effects of ambient levels of respirable particulate matter (PM) on healthy, young-adult population. Atmos. Environ. https://doi.org/10.1016/j.atmosenv.2015.10.039

Smit, R., Brown, a. L., Chan, Y.C., 2008. Do air pollution emissions and fuel consumption models for roadways include the effects of congestion in the roadway traffic flow? Environ. Model. Softw. 23, 1262-1270. https://doi.org/10.1016/j.envsoft.2008.03.001

Smit, R., Ntziachristos, L., Boulter, P., 2010. Validation of road vehicle and traffic emission models - A review and meta-analysis. Atmos. Environ. 44, 2943-2953. https://doi.org/10.1016/j.atmosenv.2010.05.022

Smit, R., Poelman, M., Schrijver, J., 2008. Improved road traffic emission inventories by adding mean speed distributions. Atmos. Environ. 42, 916-926. https://doi.org/10.1016/j.atmosenv.2007.10.026

Vieira da Rocha, T., Can, A., Parzani, C., Jeanneret, B., Trigui, R., Leclercq, L., 2013. Are vehicle trajectories simulated by dynamic traffic models relevant for estimating fuel consumption? Transp. Res. Part D Transp. Environ. 24, 17-26. https://doi.org/10.1016/j.trd.2013.03.012

Vieira da Rocha, T., Leclercq, L., Montanino, M., Parzani, C., Punzo, V., Ciuffo, B., Villegas, D., 2015. Does traffic-related calibration of car-following models provide accurate estimations of vehicle emissions? Transp. Res. Part D Transp. Environ. 34, 267-280. https://doi.org/10.1016/j.trd.2014.11.006

Xu, X., Liu, H., Anderson, J.M., Xu, Y., Hunter, M.P., Rodgers, M.O., 2016. Estimating ProjectLevel Vehicle Emissions with VISSIM and MOVES-Matrix. 95th Annu. Meet. Transp. Res. Board.

Zallinger, 2009. EVALUATION OF A COUPLED MICRO-SCOPIC TRAFFIC SIMULATOR AND INSTANTANEOUS EMISSION MODEL. J. Chem. Inf. Model. 53, 1689-1699. https://doi.org/10.1017/CBO9781107415324.004

Zhang, K., Batterman, S., Dion, F., 2011. Vehicle emissions in congestion: Comparison of work zone, rush hour and free-flow conditions. Atmos. Environ. 45, 1929-1939. https://doi.org/10.1016/j.atmosenv.2011.01.030 